\title{
Studying the Mechanical Properties of Rigid Pavement Reinforced with Single and Hybrid Fibers
}

\author{
Marwa Ahmed Moustafa ${ }^{1}{ }^{* *}$, Arafa. M. A. Ibrahim ${ }^{1}$, Hemdan Okasha Ahmed ${ }^{1}$, Farag Khodary ${ }^{1}$, \\ Yehia A. Hassanean ${ }^{2}$ \\ ${ }^{1}$ Faculty of Engineering, Qena University, Egypt \\ ${ }^{2}$ Faculty of Engineering, Assiut University, Egypt
}

Received July 11, 2021; Revised August 23, 2021; September 21, 2021

\section{Cite This Paper in the following Citation Styles}

(a): [1] Marwa Ahmed Moustafa, Arafa. M. A. Ibrahim, Hemdan Okasha Ahmed, Farag Khodary, Yehia A. Hassanean, "Studying the Mechanical Properties of Rigid Pavement Reinforced with Single and Hybrid Fibers," Civil Engineering and Architecture, Vol. 9, No. 6, pp. 1877-1899, 2021. DOI: 10.13189/cea.2021.090620.

(b): Marwa Ahmed Moustafa, Arafa. M. A. Ibrahim, Hemdan Okasha Ahmed, Farag Khodary, Yehia A. Hassanean (2021). Studying the Mechanical Properties of Rigid Pavement Reinforced with Single and Hybrid Fibers. Civil Engineering and Architecture, 9(6), 1877-1899. DOI: 10.13189/cea.2021.090620.

Copyright $\odot 2021$ by authors, all rights reserved. Authors agree that this article remains permanently open access under the terms of the Creative Commons Attribution License 4.0 International License

\begin{abstract}
High strength concrete (HSC) is the most widely used material and is presented in many different constructions such as rigid pavement. Concrete has a low tensile strength, limited fatigue life, and is characterized by brittle failure resulting in almost complete loss of loading capacity. HSC reinforced with fibers has displayed great performance in both fresh and hardened states. Recently, the use of single fiber has increased in the rigid pavement and the study of its effect on the properties of concrete. It was found that there is a need to study and compare the effect of adding hybrid fiber to concrete mixture to improve the behavior and properties of concrete. This study investigates the optimization of HSC reinforced with steel fiber by different percentages $(0 \%$ to $1 \%)$, polypropylene fiber $(0.0 \%$ to $0.26 \%)$ and the hybridization of steel fiber and polypropylene fiber as $1 \%$ volumetric fractions $(0.8 \%+0.2 \%),(0.7 \%+0.3 \%)$ and $(0.6 \%+0.4 \%)$, respectively. The slump value, compressive strength, tensile strength, and flexural strength are determined. Abrasion resistance and water absorption are also measured. The fiber percentage is adjusted to alter the brittle failure. The results showed that adding fibers to the concrete mixture decrease both slump and abrasion, while increasing permeability, tensile and compressive strength.
\end{abstract}

Keywords Single Fiber RC, Hybrid Fiber RC, Polypropylene Fiber RC, Steel Fiber RC, Rigid Pavement

\section{Introduction}

The foundation of infrastructure improvement in any country is the development of roads and highways. Therefore, the use of concrete slabs (rigid pavement) in the design of roads instead of asphalt slabs (fixable pavement) is the best choice in terms of the ability to withstand under heavy traffic loading [1], as well as the cheapness of the materials used in its manufacture, which provide durable service life, increase the maintenance period and its tolerance to the difference in temperatures in the rise and fall more than asphalt slabs, despite the previous advantages that characterize normal concrete.

Concrete is one of the most common man-made building materials in the world. It can be obtained by mixing cementations materials, potable water, sand, and gravel (Aggregate). The most important factors that help increase the compressive strength in concrete are the strength of the aggregate, and the cohesion of the cement paste. It has some defects, represented in its weak resistance to tensile strength, so some cracks appear on it when exposed to any increased tensile stress. This requires daily maintenance work to treat these cracks, as well as when increasing the ductility in the concrete industry, which gives a week in the strength of concrete used.

Therefore, it was necessary to study new techniques to increase concrete compressive strength by using HSC. HSC is produced by adding mineral and chemical 
admixtures. IS 456-2000 suggests using silica fume, fly ash, ground granulated blast furnace slag (GGBFS), metakaolin, and rice husk ash in the production of concrete. Due to the progress in the construction of concrete structures from skyscrapers, huge commercial malls, and others, this required the use of HSC.

$\mathrm{HSC}$ is characterized by a strength ranging from 60 to $80 \mathrm{MPa}$, Increasing the compressive strength of HSC helps the architect to be well organized in his designs by using elements with fewer dimensions to transfer loads as well as greater availability in spaces and less weight of concrete compared with normal concrete. Because of controlling the quality of the manufacture of this type of concrete, it is necessary to use some materials such as complimentary cement materials (silica fume) and additives such as superplasticizers that help reduce cement consumption as well as reduce voids inside the concrete, increase the compressive strength of concrete, reduce permeability and increase concrete durability.

Undoubtedly, HSC is characterized by its increased compressive forces and it has low resistance to the tensile forces exposed to it, due to the weak bonding forces between cement paste and aggregates over time. When exposed to greater loads, it causes the concrete to break. Moreover, concrete has some deficiencies such as low post cracking capacity, brittleness, low ductility, limited fatigue life, inability to accommodate large deformations, and low impact strength [2]. Utilize randomly oriented separated fibers that initiate, spread, or incorporate crack. It is the best way to improve all the deficiencies of concrete is. Fiber Reinforced Concrete (FRC) is a type of concrete in which randomly distributed fibers are used in the concrete mixture to strengthen the tensile strength of the concrete. In addition to improvement in many concrete properties, such as post-peak ductility, fatigue strength, and impact strength, there are many types of fiber in different shapes, lengths, and sizes, depending on the material used in the manufacture of this type, including:

a) Steel fibers with a diameter ranging from $0.25-0.76$ $\mathrm{mm}$ and having a variety of shapes, including crimped, straight, twisted, hooked, ringed, and paddled ends.

b) Glass Fibers which are straight and their diameter ranges from 0.005 to $0.015 \mathrm{~mm}$ (may be bonded together to form elements with diameters of 0.13 to $1.3 \mathrm{~mm}$ )

c) Natural fibers extracted from cotton, asbestos, wood, bamboo, coconut, horse hair and wool. These fibers are of different shapes and sizes and are not equal.

d) Polypropylene fiber has a variety of shapes, including fibrillated, plain, twisted, and buttoned ends.

e) Other synthetic fibers have a diameter range from 0.02 to $0.38 \mathrm{~mm}$. it likes kevlar, nylon, and polyester.

The main properties and features of FRC which make it more-granulated favourite than steel reinforcement bars are:
1. In contrast to steel bars, the fibers can vary in length but are still relatively short and closely spaced.

2. The steel reinforcement bars are placed only where they are needed, whilst the fibers are distributed throughout the mixture.

3. The concrete containing fibers for reinforcement is tougher and more resistant to impact than ordinary concrete.

4. In general, fibers cannot be replaced in place of steel bars in the main tension places in the structural element.

The fibers are not added to improve the strength, but their addition automatically increases strength [3], [4] and [5]. The fundamental role of fiber in FRC is to control the plastic shrinkage cracks and drying shrinkage cracks. One of its most important features is that it works to reduce the permeability of concrete, including reducing the bleeding of water. The bending properties of concrete are also affected by many properties of the fibers, such as the type of fibers, volume fraction, geometry, length, interfacial properties between the fibers and the matrix, and so on [6]-[7].

The most notable disadvantages of using fiber in concrete are the loss of workability, difficulty of pouring concrete, and increased amounts of trapped air inside the concrete. That may reduce the strength and durability of concrete. Hence, the direction began towards the FRC industry to be high workability, allowing the concrete to flow and fill the crowded sections with reinforcement without separating the concrete components. The mechanical performance of FRC mainly depends on the resistance of the concrete, the size of the specimen that was tested, the preparation method, and the aggregate size. The four characteristics of the fiber which will be used are:

1. The properties of the material from which it is made, e.g., resistance, rigidity and the Poisson coefficient.

2. The shape of the fiber, i.e., it can be linear, hooked end, twisted, curly, etc.

3. The interface properties, i.e., adhesion, friction, and the mechanical bond between the fibers and the mixture, the fiber's superficial texture, its geometry, and its aspect ratio (length/diameter).

4. The fiber content of the concrete mixture [3].

One of the most important factors influencing the selection of fibers is the aspect ratio, where the typical width to length ratio ranges from about 30 to 150 for the length of the fibers ranges from 6 to $75 \mathrm{~mm}$. The random fibers in the concrete mixture delay the formation and spread of cracks and improve the strength and concrete ductility. Recent research indicates that microfibers are better in impact resistance compared with longer fibers. In addition, they improve pre-crack tensile strength, post-peak ductility performance, impact strength, and fatigue strength [4]. 
Any type of fiber has been used to reinforce concrete, such as steel, glass, and polyethylene fibers [5], [6]and [8]. According to [9], steel fibers are the most commonly used fiber in UK $(50 \%)$, followed by polypropylene fibers $(20 \%)$ and glass fibers $(5 \%)$, with other types of fiber making up 25\% (see Figure 1).

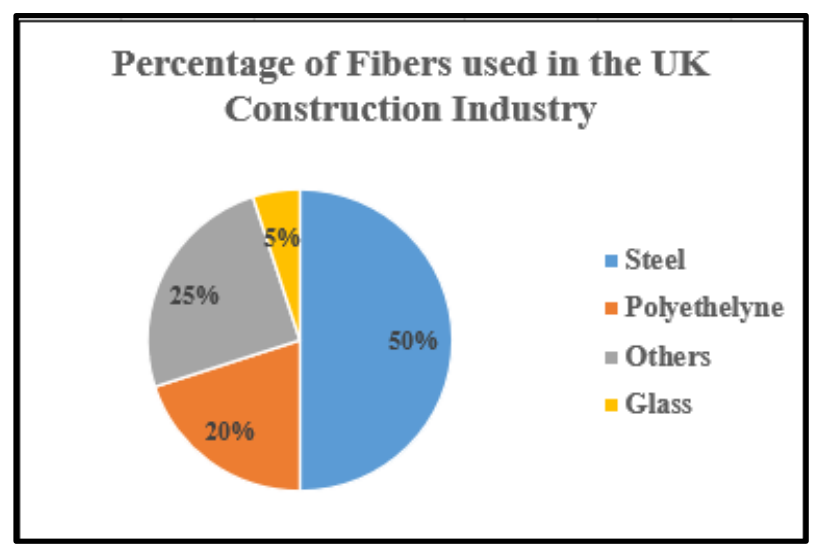

Figure 1. Percentage of fibers used in the UK construction industry [7]

[10], [11] and [12] carried out experimental tests to investigate the mechanical behavior of this type of concrete under tensile stress, fatigue, or even impact. The use of steel fiber reinforced concrete (SFRC) has been widely spread in applications such as rigid pavements and precast elements. Despite the superiority of SFRC, there are some drawbacks. Yet, no such accidents have been reported [13]. Another possible drawback, for aggressive exposure conditions, is that corrosion of the surface could occur, eventually affecting the appearance of the surface.

[14] and [15] proved that adding polymeric fibers improve the mechanical properties, durability, and serviceability of the structure. This has also been shown in practice by [16] and [17]. In recent years polypropylene fiber (PPF) have become widely used in various industries because they are relatively cheap, easy to split into finer sizes, durable in the environment of cement matrix, and are rust-free. PPF provide lightweight bulk. They are lighter than water and all other fibers. The PPF melting point and water absorption are about $165^{\circ} \mathrm{C}$, it remains flexible at around $-55^{\circ} \mathrm{C}, 0.3 \%$ after 24 hours, respectively. Adding of PPF to concrete mix can improve mix cohesion, resistance to explosive spalling in the case of a severe fire, impact resistance, pumpability over long distances, freeze-thaw resistance, and resistance to plastic but the use of PPF inside concrete to improve pressure and tensile resistance is not equivalent to that using SF.

From the foregoing, the use of one type of fiber inside the concrete improves the properties of FRC at a limited level, so the use of Hybrid fiber reinforced concrete (HFRC) was directed.

The use of hybrid fibers in concrete has enabled the development of tailor-made concretes that suit the mechanical and durability requirements of the structure. HFRC is a multiphase composite material, in which the concrete contains two or more fibers combined [18] and [19]. SF is the main component in HFRC because it is characterized by a longer length and a higher modulus of elasticity compared to other types of fibers. The rest of the fibers also control cracks and their spread. Because SF is a good conductor of electricity and magnetic fields, its content must be reduced to a certain level. The hybrid fiber system is characterized by the fact that it consists of the basic type of fibers with the largest percentage, which makes the concrete stronger and stiffer. The second type added improves the stress of the first crack and the final strength. Also, this type of reinforcement is used to increase the utilization of the different properties of the fibers and their behavior to improve the different properties of concrete.

Using hybrid fibers means that the properties of different fibers improve the performance of concrete in various loading stages, play complementary roles in the concrete, and achieve the positive confounding effect of the fiber [20] and [21]. The use of hybrid fibers in concrete has increased on a large scale and used in pavements, rigid pavements, earthquake and explosive resistant structures, tunnel linings, hydraulic structures, as well as in stabilizing rocky slopes and other.

[23] studied the mechanical properties of the concrete mixture. The concrete was reinforced with $0.036 \% \mathrm{PPF}$ while added individually. After that, they were added together with SF of $1 \%$ to form a hybrid fiber. It improves the compressive strength by using hybrid fibers as soon as improves split tensile strength and flexural strength.

[24] studied the mechanical properties of concrete such as (compressive strength, split tensile and flexural strength) reinforced with hybrid fibers (SF1\%+PPF0.035\%). This studding proved that addition of hybrid fibers improve and increase the values of compressive, split tensile and flexural strength.

[25] studied the effect of adding Three types of SF (straight, hooked-end and corrugated fiber) and PPF. The flexural behavior in terms of load-deflection curves, toughness, load and deflection characteristics, cracking properties as well as the synergetic effect of hybrid fibers is studied. This study proved that by using hybrid fibers improve flexural behavior, the increase of volume fractions of both SF and PPF increases the mechanical properties of concrete. In addition, using hooked-end fibers and corrugated are better failure behavior than sample with straight fibers. Using HFRC gives better result in all tests.

Finally, whilst several studies have investigated the behavior of single and HFRC, not the conclusions have agreed. Consequently, there has been some hesitation in the design of structural elements within civil infrastructure. Experimental results are limited and evidence for individual scenarios remains to be found. Moreover, in each of the above studies, steel fibers and polypropylene fibers are hybridized in large doses. The objectives of this 
work are:

1. To investigate the mechanical properties of FRC reinforced with single fibers such as SF or PPF.

2. To investigate the effect of fiber content on the mechanical properties of FRC reinforced with single fibers.

3. To investigate the effect of adding more than one fiber type (SF+PPF) on the mechanical properties of FRC.

4. To determine the optimum fiber content of single and HFRC on fresh and hardened reinforced concrete properties.

\section{Experimental Program}

\subsection{General Overview}

This study presents experimental tests carried out on concrete mixes using SF, PPF, and HFRC aims to investigate the effect of both fiber type and fiber content. The experimental program consisted of four groups. The first group contains only one mix without fiber while second group contains four mixes with $0.2 \%, 0.4 \%$, $0.75 \%$ and $1.0 \% \mathrm{SF}$. The third group contains four mixes with $0.066 \%, 0.12 \%, 0.185 \%$ and $0.26 \% \mathrm{PPF}$ while fourth group contains three hybrid mixes with $\mathrm{SF} 0.8 \%+$ PPF0.2\%, SF0.7\% + PPF $0.3 \%$ and SF0.6\% + PPF $0.4 \%$. Fresh and hardened properties of mixes are measured like the slump, and compressive strength (after 7 and 28 days), split tensile strength, flexural strength, abrasion resistance, and water absorption of hardened properties of concrete with different percentages of fibers. To achieve the main objectives of this research, a large experimental program was carried out, as presented in Table 1. These groups contain 12 concrete mixtures of FRC and a total of 216 samples were prepared and tested.

Table 1. Mix proportions for the design mixes

\begin{tabular}{|c|c|c|c|c|c|c|c|c|c|c|}
\hline \multirow{2}{*}{ Series } & \multirow{2}{*}{ Mix } & \multirow{2}{*}{$\begin{array}{c}\text { Cement } \\
\mathrm{Kg}\end{array}$} & \multicolumn{2}{|c|}{ Coarse aggregate } & \multirow{2}{*}{$\begin{array}{c}\text { Sand } \\
\mathrm{kg}\end{array}$} & \multirow{2}{*}{$\begin{array}{c}\text { Water } \\
\text { liter }\end{array}$} & \multirow{2}{*}{$\begin{array}{c}\text { Silica } \\
\mathrm{Kg}\end{array}$} & \multirow{2}{*}{$\begin{array}{l}\text { Admixture } \\
\text { liter }\end{array}$} & \multirow{2}{*}{$\begin{array}{l}\mathrm{SF} \\
\mathrm{Kg}\end{array}$} & \multirow{2}{*}{$\begin{array}{r}\mathrm{PPF} \\
\mathrm{Kg}\end{array}$} \\
\hline & & & Size (1) & Size (2) & & & & & & \\
\hline A & HSC & \multirow{12}{*}{500} & \multirow{12}{*}{659.8} & \multirow{12}{*}{439.85} & \multirow{12}{*}{618} & \multirow{12}{*}{180.27} & \multirow{12}{*}{60} & \multirow{12}{*}{13.31} & 0 & 0 \\
\hline \multirow{4}{*}{ B } & SF0.2\% & & & & & & & & 16.8 & 0 \\
\hline & SF0.4\% & & & & & & & & 30 & 0 \\
\hline & SF0.75\% & & & & & & & & 58.88 & 0 \\
\hline & $\mathrm{SF} 1 \%$ & & & & & & & & 78.50 & 0 \\
\hline \multirow{4}{*}{ C } & PPF0.066\% & & & & & & & & 0 & 0.6 \\
\hline & PPF $0.12 \%$ & & & & & & & & 0 & 1.08 \\
\hline & PPF $0.19 \%$ & & & & & & & & 0 & 1.68 \\
\hline & PPF $0.26 \%$ & & & & & & & & 0 & 2.4 \\
\hline \multirow{3}{*}{$\mathrm{D}$} & SF0.8 $\%+$ PPF $0.2 \%$ & & & & & & & & 62.8 & 1.82 \\
\hline & SF $0.7 \%+$ PPF $0.3 \%$ & & & & & & & & 54.95 & 2.73 \\
\hline & SF0.6\% $\%$ PPF0.4\% & & & & & & & & 47.1 & 3.64 \\
\hline
\end{tabular}




\subsection{The Composite Concrete Mixture}

1. Cement: Ordinary Portland cement of $52.5 \mathrm{~N}$ grade and the dosage agreed with [29].

2. Fine aggregate passed through sieve $4.75 \mathrm{~mm}$ had a fineness modulus of 2.50 to 3.50 and fine materials contents not greater than $4 \%$ limited was $5 \%$. The sieve analysis results and other physical and chemical properties of the sand were agreed with ECP203[22].

3. Coarse aggregate contained two sizes of aggregate $60 \%$ from aggregate with maximum size $13 \mathrm{~mm}$, and $40 \%$ from aggregate with maximum size $25 \mathrm{~mm}$. The abrasion coefficient of this aggregate was $25 \%$. The sieve analysis results, and other physical and chemical properties of the coarse aggregate were agreed with ECP203[22]

4. Drinking water was used for mixing and curing. All mixtures in this investigation have $\mathrm{w} / \mathrm{c}=0.35$.

5. Sikament-NN (high range water reducing concrete admixture) was used in all mixes.

6. Silica fume with specific gravity 2.2 was used to obtain the higher strength of concrete Table (2) shows the physical and chemical properties of silica fume (from the Egyptian Ferroalloys Company (EFACO).

7. The fibers used in this study were crimped SF and PPF. The properties of fibers are shown in Table 3. The shapes of all fibers are shown in Figure 2.

The mixture proportions were calculated according to the Egyptian code as shown in Table 3. To achieve the mean strength of M60, $60 \mathrm{MPa}$ concrete was used for the control mixture. Firstly, cement, sand, coarse aggregate, silica fume, and fibers were mixed for two minutes before adding the water with the superplasticizer. The mixing continued for a further four minutes until the mixing time was considered sufficient for the dispersion of the fibers in the mix without causing a "balling" effect. Next, the specimens were vibrated in moulds and then stored under plastic covers for one day. After removing the samples, they are all placed in a tank filled with potable water for treatment until the day of the test. Each mix contained three cube specimens side length $150 \mathrm{~mm}$, six cube specimens side length $100 \mathrm{~mm}$, three cube specimens side length $70 \mathrm{~mm}$, three-cylinder specimens $150 \mathrm{~mm}$ diameter and $300 \mathrm{~mm}$ long, and three prisms $(100 \mathrm{~mm} \times 100 \mathrm{~mm} \times$ $500 \mathrm{~mm}$ ).

Table 2. Physical and chemical properties of silica fume

\begin{tabular}{|c|c|c|}
\hline Property & Measured values & Limitations \\
\hline \multicolumn{3}{|c|}{ Physical properties } \\
\hline Color & Light gray & -- \\
\hline Specific gravity & 2.15 & -- \\
\hline Bulk density $\left(\mathrm{kg} / \mathrm{cm}^{3}\right)$ & 340 & $250-450$ \\
\hline \multicolumn{3}{|c|}{ Chemical properties: } \\
\hline $\mathrm{SiO}_{2}$ & $97 \%$ & $90 \% \min$ \\
\hline $\mathrm{C}$ & $0.5 \%$ & $1 \% \max$ \\
\hline $\mathrm{Fe}_{2} \mathrm{O}_{3}$ & $0.5 \%$ & $1.5 \% \max$ \\
\hline $\mathrm{Al}_{2} \mathrm{O}_{3}$ & $0.2 \%$ & $1 \% \max$ \\
\hline $\mathrm{CaO}$ & $0.2 \%$ & $1 \% \max$ \\
\hline $\mathrm{MgO}$ & $0.5 \%$ & $1.5 \% \max$ \\
\hline $\mathrm{K}_{2} \mathrm{O}$ & $0.5 \%$ & $1.5 \% \max$ \\
\hline $\mathrm{Na}_{2} \mathrm{O}$ & $0.21 \%$ & $0.5 \% \max$ \\
\hline $\mathrm{SO}_{3}$ & $0.16 \%$ & $0.2 \% \max$ \\
\hline $\mathrm{H}_{2} \mathrm{O}$ & $0.5 \%$ & $0.8 \% \max$ \\
\hline $\mathrm{Cl}$ & $<0.01 \%$ & $0.05 \% \max$ \\
\hline $\mathrm{PH}$ & $6 \%$ & $\pm 1 \% \max$ \\
\hline
\end{tabular}

Table 3. Properties of the used fibers.

\begin{tabular}{|c|c|c|}
\hline Fiber Properties & $\mathrm{SF}$ & PPF \\
\hline Average fiber length $\mathrm{L}$ & $60 \mathrm{~mm}$ & $16 \mathrm{~mm}$ \\
\hline Average fiber width $d$ & $0.75 \mathrm{~mm}$ & $\begin{array}{l}\text { rectangular cross } \\
\text { section }\end{array}$ \\
\hline Aspect ratio $(\mathrm{L} / \mathrm{d})$ & 80 & - \\
\hline Breaking strength $(\mathrm{MPa})$ & $>1100$ & - \\
\hline Tensile strength & $>800$ & $640 \mathrm{MPa}$ \\
\hline Ultimate elongation (\%) & $<2$ & - \\
\hline Specific gravity & 7.85 & $0.90-0.92$ \\
\hline Density $\mathrm{kg} / \mathrm{cm}^{3}$ & 7850 & 920 \\
\hline Shape of steel & Crimped & straight \\
\hline Electrical conductivity & high & low \\
\hline Youngs modulus (GPa) & 210 & 10Gpa \\
\hline
\end{tabular}

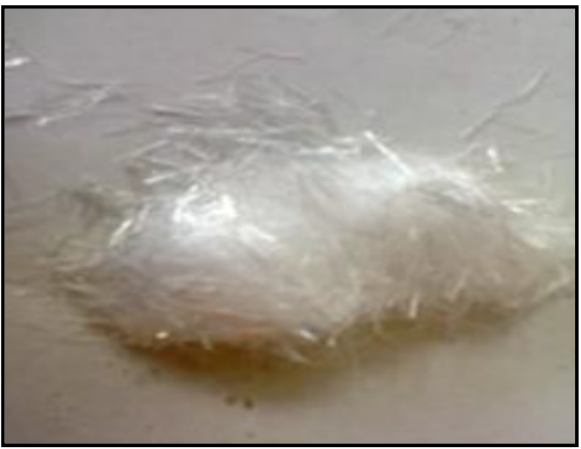

(b)

Figure 2. The shapes of fibers, a) Steel Fibers, b) Polypropylene Fiber 


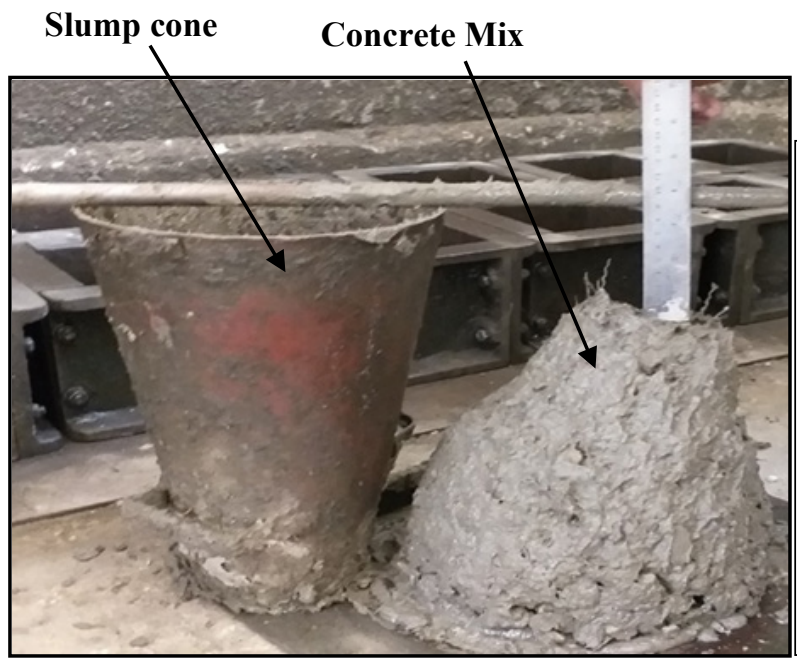

Figure 4. Slump test

\section{Compression}

Testing Machine Cube Specimen

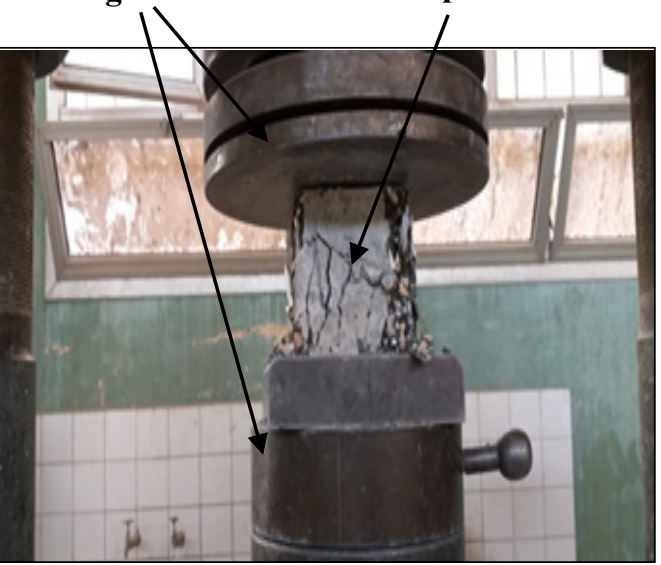

Figure 4. Test setup for Compressive strength

\subsection{Devices and Test Set Up}

Details of the experiment program are shown in the following sections.

\subsubsection{Workability}

The definition of the workability is the way of handling and mixing a new mixture of concrete or mortaring and placing it easily. It is also known as the ability of the concrete mixture to form and fill the shape of a mold without affecting the quality of concrete. There are many factors that affect the operation of fresh concrete, namely the shape of the aggregate, its classification, water content, mixing proportions, the use of fibers and the use of superplasticizers.

The best method for knowing the workability of concrete is measure the slump value of fresh concrete. The addition of fibres on concrete mix can change the water cement ratio and, as a result, reduce its slump. It is measured according to ECP203[22], as shown in Figure 3.

\subsubsection{Compressive Strength}

The compressive strength of concrete is the most common performance measure used by civil engineers in designing buildings. It is measured by crushing specimen cubes of concrete in a compression testing machine after 7 and 28 days. Measurements were made according to ECP203[22], as shown in Figure 4.

\subsubsection{Split tensile Strength}

Split tensile strength relates to its tension strength of concrete. This is obtained by performing a split tensile test on a concrete specimen. The concrete specimen in this test is taken as cylindrical in shape of $30 \mathrm{~cm}$ length and $15 \mathrm{~cm}$ diameter. Tensile strength for a concrete specimen is defined as the tensile stresses developed at which the concrete specimen cracks. These specimens were tested in a compression testing machine as shown in Figure 5. In each category, three cylinders were tested, and their average value is considered. Split tensile strength (T) was calculated as follows:

$$
\text { Tension Strength, } T=\frac{2 P}{\pi D l}
$$

where $P=$ failure load, $D=$ diameter of cylinder, $\mathrm{L}=$ length of cylinder.

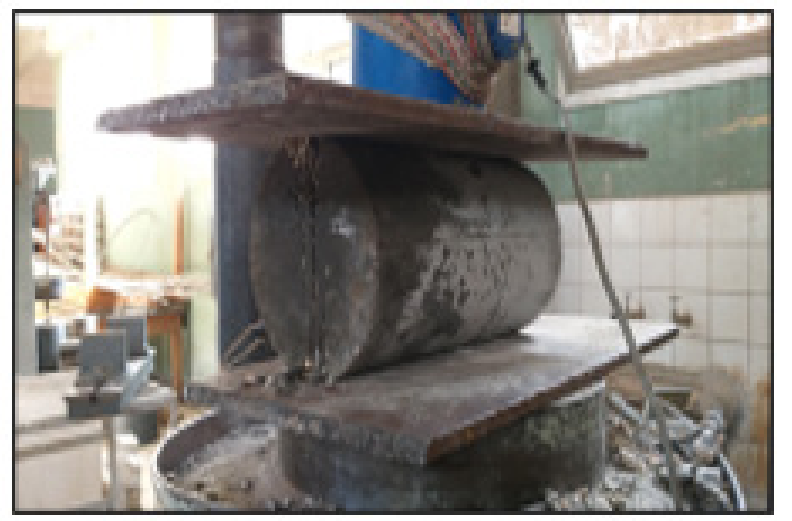

Figure 5. Test setup for Indirect tensile strength

\subsubsection{Flexural Strength Test}

The flexural strength specimens were tested under four-point loading over an effective span of $300 \mathrm{~mm}$ on a flexural testing machine. Load and corresponding deflections were noted up to the point of failure. In each mix, three beams were tested, and their average value is also considered. The flexural strength was calculated as follows:

$$
\begin{aligned}
& \qquad \begin{array}{c}
M=\frac{p}{2} \times \frac{l}{3}=\frac{p l}{6} \\
\text { Flexural strength, } F_{c t}=\frac{6 M}{b \times t^{2}}=\frac{p l}{b \times t^{2}}
\end{array}
\end{aligned}
$$

Where: $p=$ failure load, $l=$ effective span length $=$ 
$300 \mathrm{~mm}, b=$ width of specimen $=100 \mathrm{~mm}, t=$ depth of specimen $=100 \mathrm{~mm}$. A strain gauge was installed in the middle of each sample and a crack width measurement was installed also in one sample of the mix. These tests were done to determine flexural load-deflection curve, load-strain in concrete curve and net deflection at first-crack load as shown in Figure 6.

\subsubsection{Abrasion Resistance Test}

For the abrasion resistance test, specimens of dimension $70 \times 70 \times 70 \mathrm{~mm}$ were cast for each of mix. Firstly, all specimens were cut at a distance that fitted the existing 60 x 60 x $40 \mathrm{~mm}$ landing machine. Next, all specimens were put in an oven. Each clean sample was weighted before the test. The landing machine was installed with $9 \mathrm{~kg}$ two loads. The period allocated for the land was seven minutes and the number of revolutions exposed to the sample was 299. Landing is carried out using standard sand that has already been prepared as shown in Figure 7. Finally, the samples were weighted after the test. Samples were weighted in water and in air to determine density. Abrasion resistance was measured in terms of the depth of the abraded concrete surface and loss of mass according to ECP203[22].

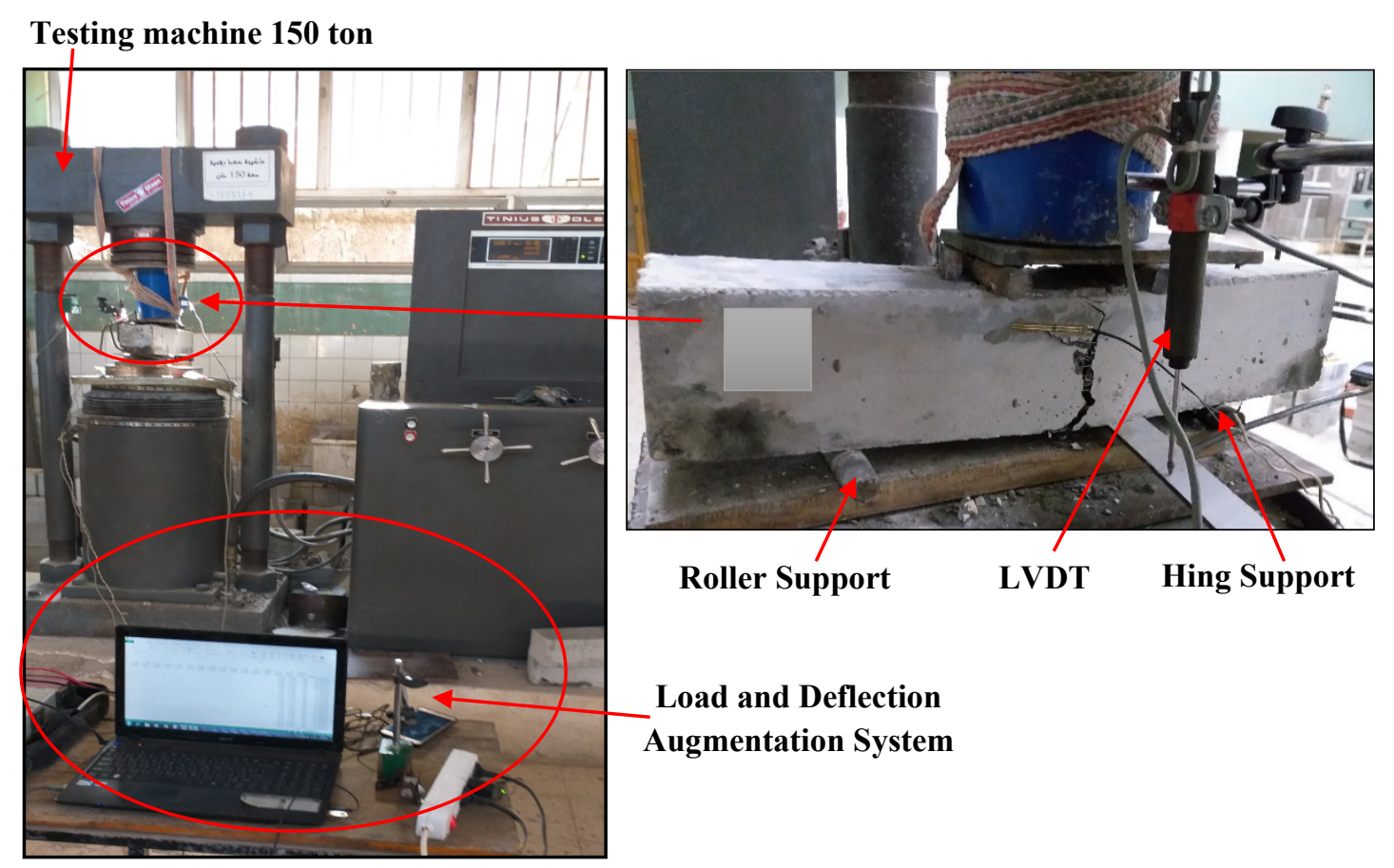

Figure 6. Flexural strength test four-point loading

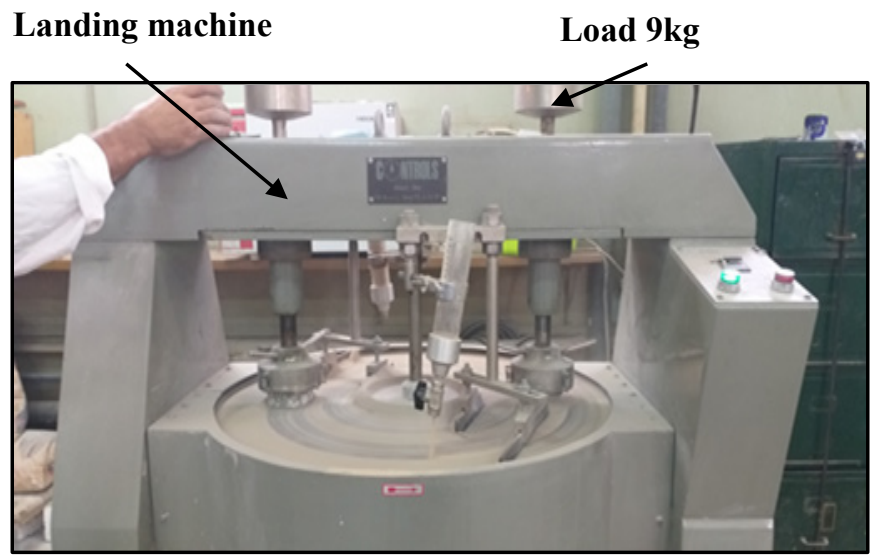

Figure 7. Test setup for Abrasion resistance test 


\subsubsection{Water Absorption Test}

There are three modes of moisture moving through the concrete: flow, diffusion, and sorption. Large pores allow easier entry of a substance, while smaller pores decrease the rate at which these substances enter the concrete. Permeability is the rate of fluid flow into concrete by these three modes. The permeability of concrete is determined by measuring water penetration or chloride penetration. The sample is weighed, dried in an oven, then reweighted under standard conditions to calculate the moisture content. For the water absorption test, specimen cubes of dimension $100 \times 100 \times 100 \mathrm{~mm}$ were cast for each of the mixtures. The water absorption test measurement was done in terms of the depth of the abraded concrete surface and the loss of mass according to ECP269 [22] as shown in Figure 8.

\section{Results and Discussion}

The effect of single fibers and hybrid fibers on the properties of HSC like workability, splitting strength, compressive strength, flexural strength, abrasion resistance, and water absorption are illustrated in Table 4 and discussed in the following sections.

\subsection{Effect of Both Fibers Type and Content on Workability of HSC}

Figure 8 shows the effect of both type and content of SF, PPF, and hybrid fiber content on the workability of fresh concrete mixtures. The slump value of the control mix was $17 \mathrm{~cm}$. Adding $0.2 \%$ to $1 \%$ crimped SF, slump values gradually decreased by $2.94 \%$ and $64.71 \%$ compared with the control mix, without fiber. This may be due to the increase of specific surface area associated with the increase in fiber content. Moreover, the SF were randomly distributed in the matrix and acted as a skeleton which eventually prevented the flow of fresh concrete and increased the internal resistance to flow, even though concrete mixtures contain plasticizers or superplasticizers. Figure 9 shows that by adding $0.066 \%$ to $0.26 \%$ total volume of PPF, slump values decreased by $23.53 \%$ to $35.29 \%$. Finally, increasing the volume of PPF in the concrete decreased the slump value slightly because PPF affect the flowability of fresh concrete, which results in a decrease in workability.

Also, Figure 9 shows the results of the slump values of all mixes. The results from the mixes consist of SF and PPF show that there is a decrease in the slump value as the volume fraction of SF increases, and the volume fraction PPF decreases. This is because the SF prevents the flow of fresh concrete and increases the internal resistance to flow. The hybrid fiber results shown in Figure 10 and Table 4 illustrate that the use of PPF as a partial replacement for SF improve the workability of the concrete with the increase in PPF content. Using SF0.6\%+PPF $0.4 \%$ of volume, the slump value decreased by $50.0 \%$ compared with control mix. It can be seen from this chart that by decreasing the percentage of SF and increasing the percentage of other fibers such as PPF in concrete, the value of the slump test increases mainly because deformed fibers increase the friction between fibers and aggregates which increases the coherence with the matrix, and thus reduces the workability.

Table 4. Mechanical properties of FRC reinforced with single and hybrid fibers

\begin{tabular}{|c|c|c|c|c|c|c|c|c|c|}
\hline \multirow{2}{*}{ Mix } & \multirow{2}{*}{$\begin{array}{l}\text { Slump } \\
\mathrm{cm}\end{array}$} & \multirow{2}{*}{$\begin{array}{l}\text { Compressive } \\
\text { strength } \\
\text { after } 7 \text { days } \\
\mathrm{kg} / \mathrm{cm}^{2}\end{array}$} & \multirow{2}{*}{$\begin{array}{l}\text { Compressive } \\
\text { strength } \\
\text { after } 28 \text { days } \\
\mathrm{kg} / \mathrm{cm}^{2}\end{array}$} & \multirow{2}{*}{$\begin{array}{l}\text { Flexural } \\
\left(\mathrm{kg} / \mathrm{cm}^{2}\right)\end{array}$} & \multicolumn{2}{|c|}{$\begin{array}{c}\text { tensile strength } \\
\mathrm{kg} / \mathrm{cm}^{2}\end{array}$} & \multirow{2}{*}{$\begin{array}{c}\text { Water } \\
\text { absorption } \\
\%\end{array}$} & \multirow{2}{*}{$\begin{array}{l}\text { Loss } \\
\text { in } \\
\text { mass } \\
\text { gm }\end{array}$} & \multirow{2}{*}{$\begin{array}{c}\text { Depth of } \\
\text { Damage } \\
\text {, mm }\end{array}$} \\
\hline & & & & & flexural & splitting & & & \\
\hline HSC $0 \%$ & 17 & 505.7 & 582.0 & 77.1 & 46.26 & 38.74 & 1.90 & 6.00 & 0.007 \\
\hline SF $0.2 \%$ & 17 & 494.9 & 575.2 & 57 & 34.20 & 35.34 & 1.96 & 4.00 & 0.005 \\
\hline SF $0.40 \%$ & 13 & 476.5 & 556.6 & 78.6 & 47.16 & 42.01 & 4.80 & 4.00 & 0.006 \\
\hline SF $0.75 \%$ & 7.5 & 568.0 & 654.8 & 51 & 30.60 & 50.17 & 2.76 & 7.00 & 0.007 \\
\hline SF $1 \%$ & 6 & 637.0 & 650.0 & 55.5 & 33.30 & 50.44 & 3.14 & 6.50 & 0.005 \\
\hline PPF $0.066 \%$ & 13 & 447.0 & 446.2 & 87 & 52.20 & 38.53 & 1.62 & 6.00 & 0.008 \\
\hline PPF $0.12 \%$ & 12.7 & 518.7 & 551.0 & 73.2 & 43.92 & 36.94 & 2.09 & 4.50 & 0.009 \\
\hline PPF $0.19 \%$ & 11 & 433.7 & 554.8 & 79.2 & 47.52 & 38.18 & 2.77 & 6.50 & 0.008 \\
\hline PPF $0.26 \%$ & 11 & 529.0 & 472.8 & 67.5 & 40.50 & 26.50 & 2.10 & 6.50 & 0.007 \\
\hline SF $0.8 \%+$ PPF $0.2 \%$ & 6 & 620.0 & 651.8 & 58.5 & 35.10 & 54.00 & 3.63 & 5.50 & 0.006 \\
\hline SF $0.7 \%+$ PPF $0.3 \%$ & 9 & 570.0 & 630.5 & 81 & 48.60 & 45.50 & 3.52 & 8.50 & 0.008 \\
\hline SF $0.6 \%+$ PPF $0.4 \%$ & 8.5 & 609.0 & 659.0 & 78 & 46.80 & 65.00 & 8.10 & 7.50 & 0.008 \\
\hline
\end{tabular}




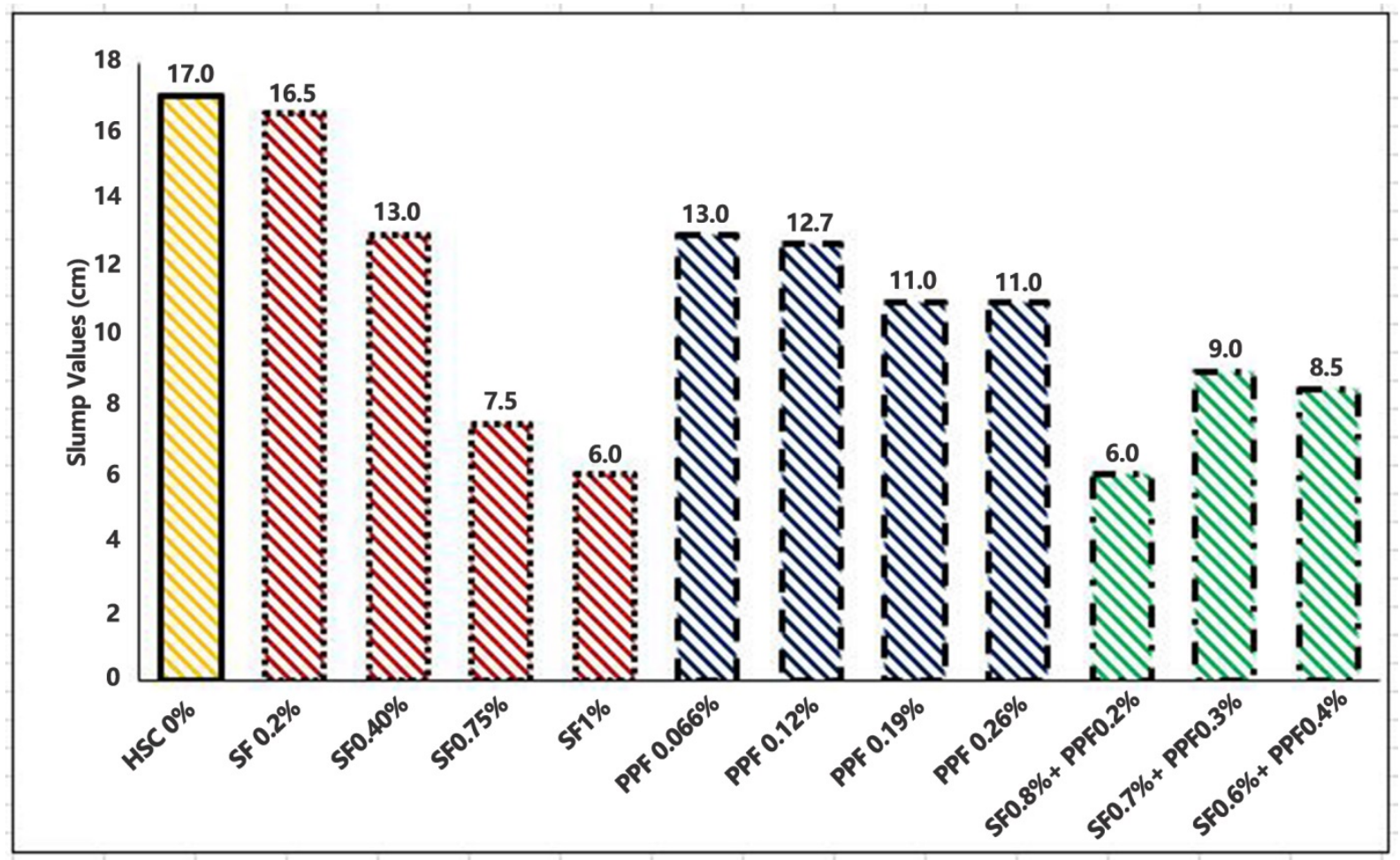

Figure 8. The effect of different volume fraction of single fibers and hybrid fibers on the slump values

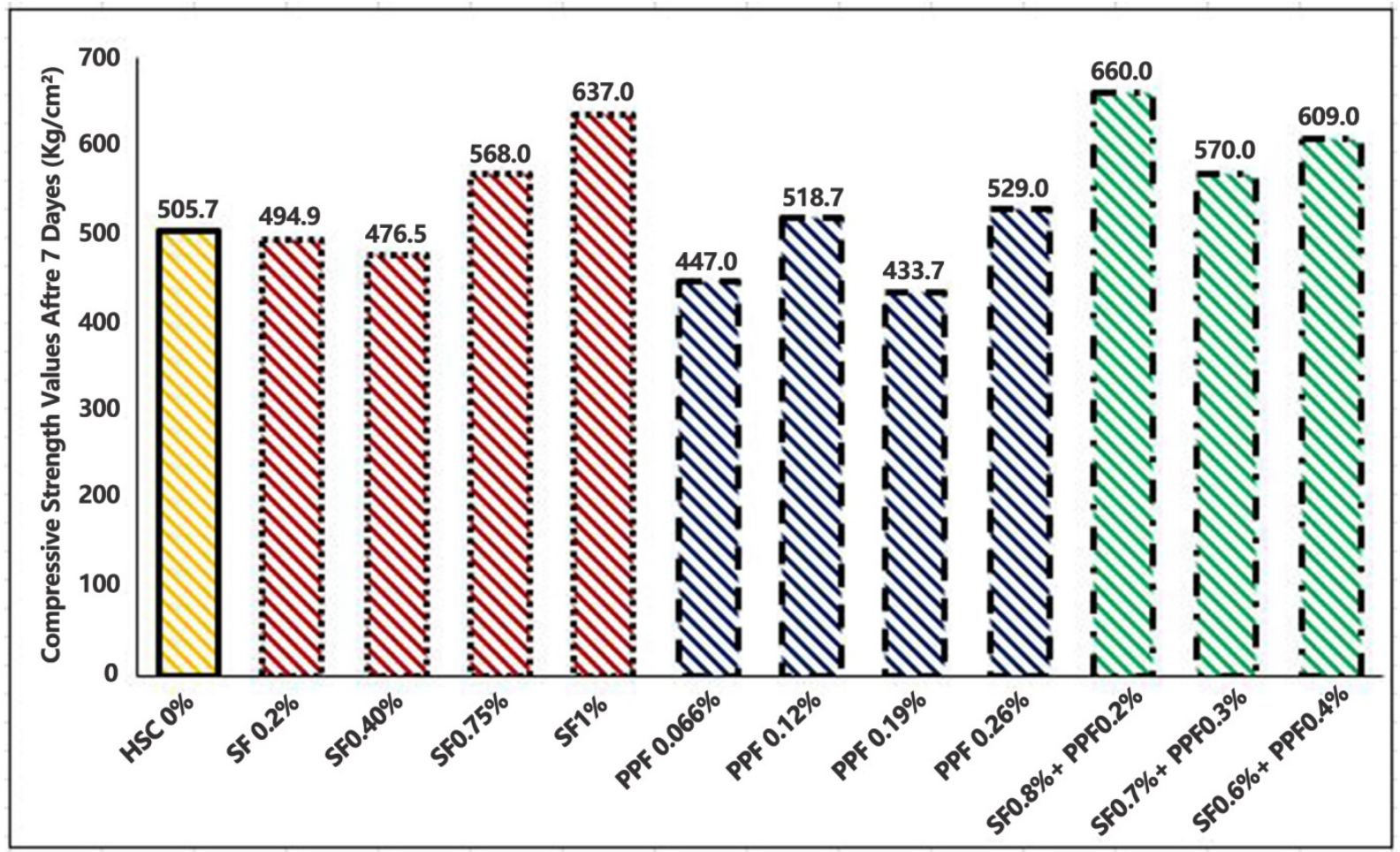

Figure 9. The Effect of Different Volume Fraction of Single Fibers and Hybrid Fibers on the Compressive Strength of High Strength Concrete After 7 Days 


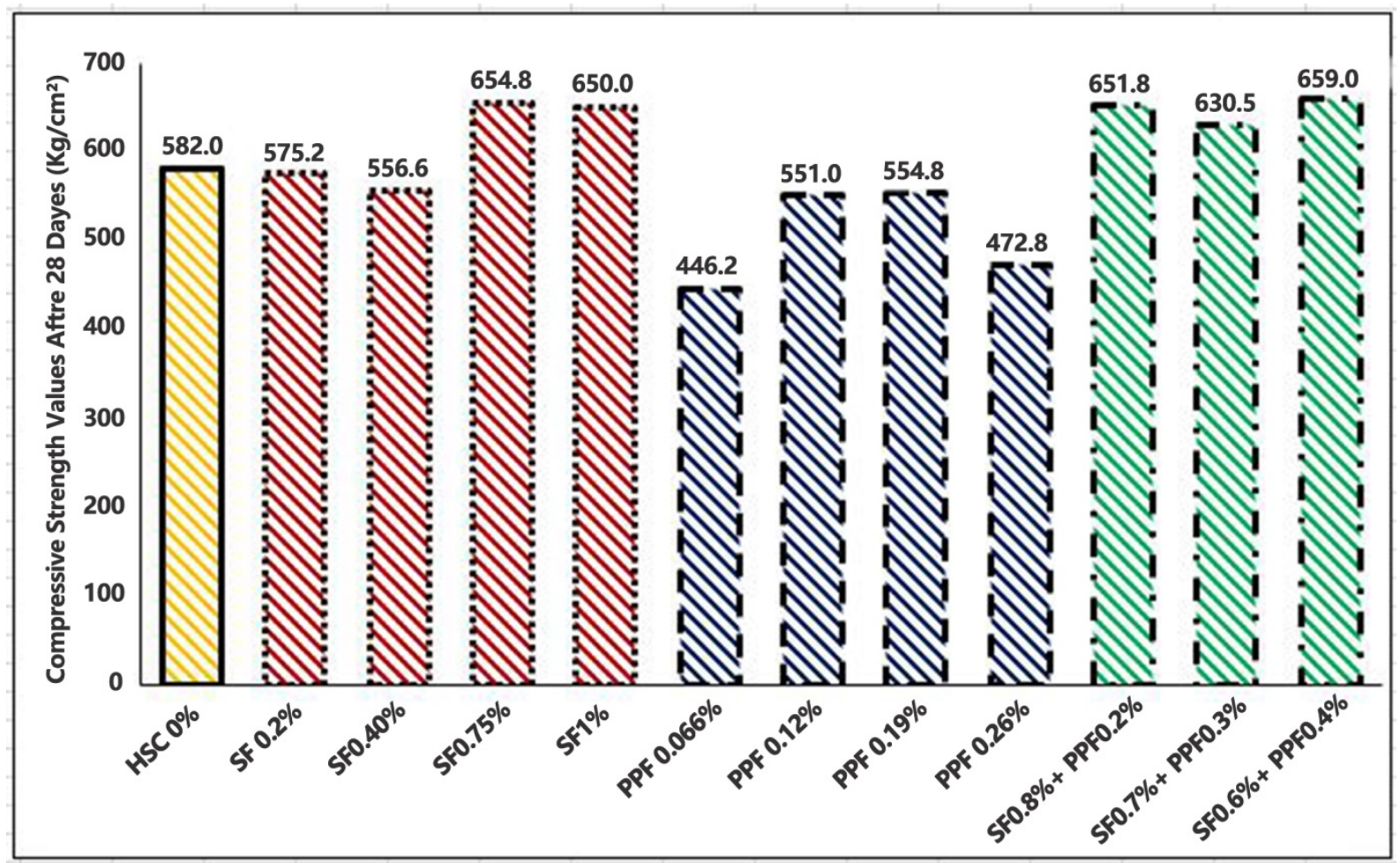

Figure 10. The Effect of Different Volume Fraction of Single Fibers and Hybrid Fibers on the Compressive Strength of High Strength Concrete After 28 Days

\subsection{Compressive Strength}

Figures 9 and 10 and Table 4 show the compressive strength value of SF, PPF and hybrid fiber reinforced concrete specimens for different fiber dosages after 7 and 28 days. The increase in compressive strength resulted from increasing control over crack formation and development under axial load. Thus, the increase in compressive strength occurred because these mixes contained fibers. The incorporation of fibers (single fiber or hybrid fiber) improves the failure pattern of concrete, in which there are distinct areas of damage in the two specimens. It was observed that the value of concrete compressive strength does not decrease. If this were to happen, the resistance would indicate the negative impact of fiber on the workability of concrete. It can be seen from Figures 10 and 11 and Table 4 that the cube compressive strength of (SF0.2\%, SF0.4\%, SF0.75 and SF1\%) increased by $(-2.13 \%,-5.77 \%, 12.32 \%$ and $26 \%)$ after 7 days, but after 28 days increased by $(-1.17,-4.37,12.5$ and $11.68 \%$ ) respectively. clearly, (PPF0.066\%, PPF0.12\%, PPF0.19\% and PPF0.26\%) shows a certain "slight effect which is $(-11.61 \%, 2.6 \%,-14.24 \%$ and $4.6 \%)$ higher than HSC after 7 days but decreased also, slightly by $(23.33 \%$, $5.33 \%, 4.7 \%$ and $18.77 \%$ ) after 28 days respectively. When the PPF was mixed with SF (SF0.8\%+PPF0.2\%, $\mathrm{SF} 0.7 \%+\mathrm{PPF} 0.3 \%$ and $\mathrm{SF} 0.6 \%+\mathrm{PPF} 0.4 \%$ ), the cube compressive strength increased $(30.51 \%, 12.7 \%$ and $20.43 \%$ ) after 7 days, but after 28 days increased by $(12.0 \%, 8.33 \%$ and $13.23 \%)$ respectively compared with
HSC. Thus, from the investigation of the results obtained from the compression test, the optimum fiber content for $\mathrm{SF}$ is $0.75 \%$ after 28 days, but at $1 \%$ of $\mathrm{SF}$, the compressive strength is higher at an early age of 7 days, and for PPF it is $0.2 \%$. It was found that the best ratio is $\mathrm{SF} 0.6 \%+\mathrm{PPF} 0.4 \%$. This percentage increases the compressive strength by $13.23 \%$ at 28 days compared with the control mix.

\subsection{Split Tensile Strength (Direct Tensile Strength):}

Figure 11 shows there is an increase in split tensile strength values for all concrete mixes containing fiber compared with the control specimen. Reinforcing concrete with fibers reduced the crack width and durability improved. From the results of the split tensile test, it is clear that the optimum fiber content for SF is $1 \%$ of the total volume of concrete, and for PPF fiber it is $0.066 \%$. Increasing in tensile strength at $1 \%$ SF was $30.20 \%$, but the decrease in split tensile strength with $0.066 \% \mathrm{PPF}$ fiber was $0.54 \%$. An increase in tensile strength was observed in all mixes containing SF because SF has greater tensile strength than any other type of fiber.

From Figure 11 it can be seen that all mixes containing a mix of fibers had to split tensile strength greater than the control mix. The increase in splitting tensile strength in Mix containing (SF0.6\%+PPF0.4\%) was $67.79 \%$ compared with the control mix. Fibers, especially steel fibers, make the concrete less brittle and more ductile. 


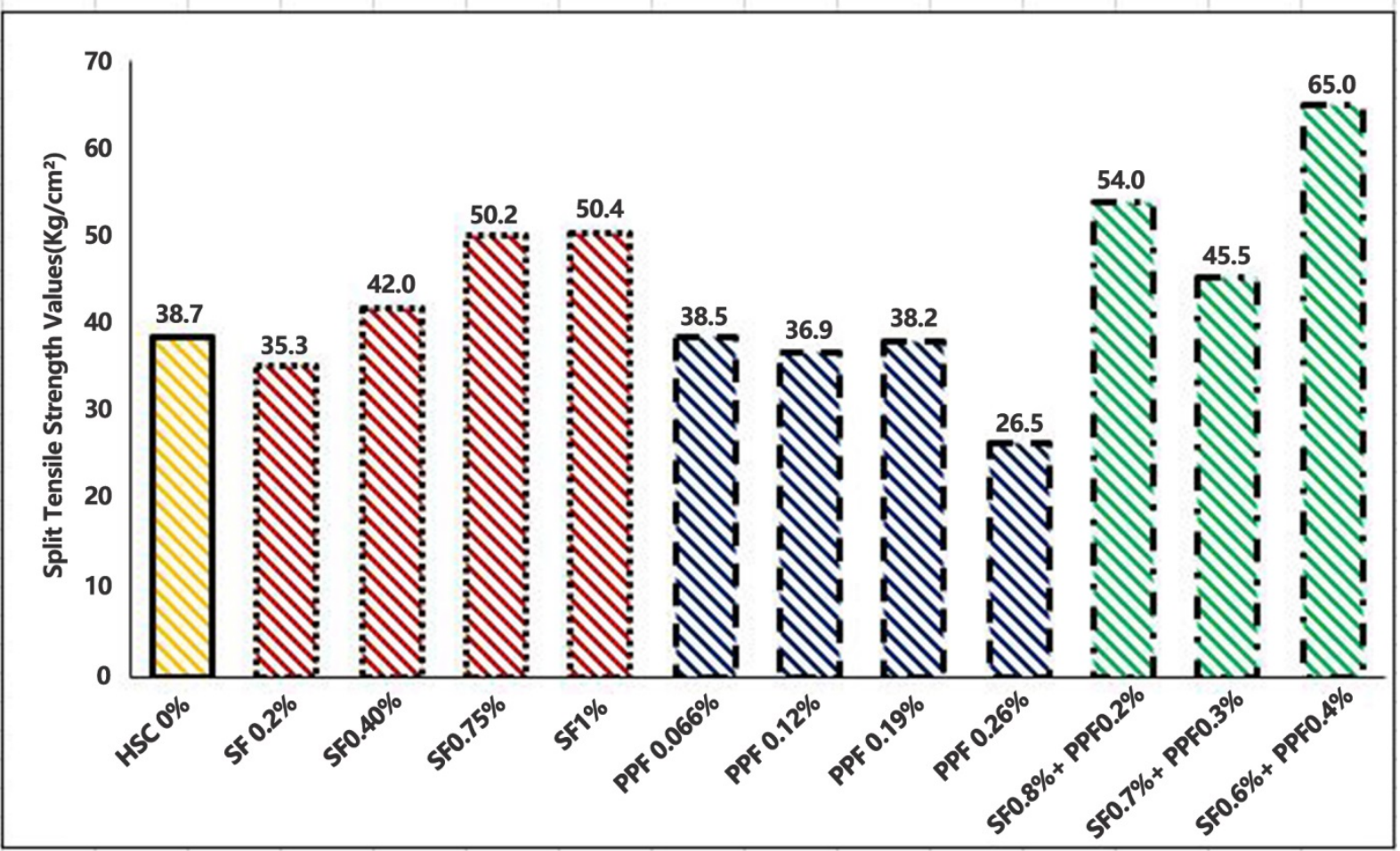

Figure 11. The Effect of Different Volume Fraction of Single Fibers and Hybrid Fibers on the Splitting Strength of High Strength Concrete After 28 Days

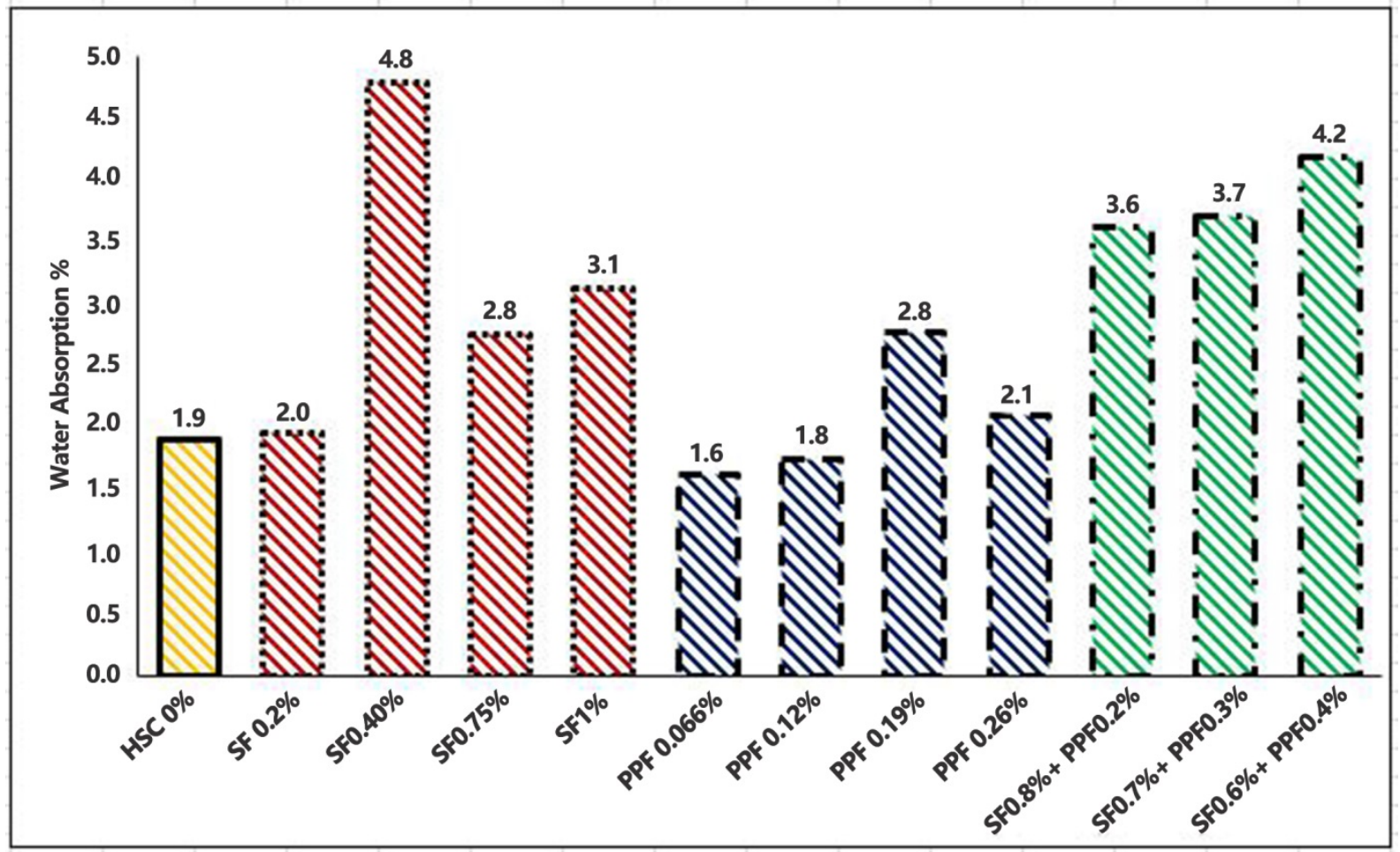

Figure 12. The Effect of Different Volume Fraction of Single Fibers and Hybrid Fibers on the Water absorption test of High Strength Concrete After 28 Days

\subsection{Water Absorption Test (Permeability)}

As the single fiber volume fraction increased in the normal curing regime, the percentage of the water absorption increased. Table 4 and Figure 12 show the water absorption results. The maximum percentage increase in water absorption values with $\mathrm{SF} 0.4 \%$ was $151.89 \%$ and with PPF $0.02 \%$ was $45.64 \%$ compared with the control mix. The permeability of concrete improved 
significantly with increasing SF content in the mixture. Increasing the content of PPF significantly improved the permeability of concrete. Different content improves the permeability of concrete slightly because it is well mixed and distributed throughout the concrete and has excellent cohesive properties. Studying the hybrid fiber was very important in order to improve the behavior of single fibers in concrete with respect to water absorption.

With SF0.6\%+PPF0.4\% the increase was $325.54 \%$ compared to the control mix. The maximum percentage increase in water absorption values was seen with $\mathrm{SF} 0.6 \%+\mathrm{PPF} 0.4 \%$.

\subsection{Abrasion Test}

Table 4 and Figure 13 show the loss in mass after the abrasion test (gm) and it can be observed that the maximum percentage increases in abrasion test values compared with control concrete with SF0.75\% was $16.67 \%$ and with PPF $0.26 \%$ was $8.33 \%$. The maximum percentage increases in abrasion values were seen with $\mathrm{SF} 0.7 \%+\mathrm{PPF} 0.3 \%$. It can be concluded that greater abrasion resistance was observed in the hybrid steel and PPF because of their geometry. In the abrasion test, the larger diameter steel fiber particles lifted large concrete pieces. On the other hand, the polypropylene fibers with their small diameter were isolated from the concrete mixture without removing big concrete pieces.

From Table 4 and Figure 13, it can be seen that the abrasion resistance increases when hybrid fibers are added to HSC. The observed increase with SF70+PPF30\% was $41.67 \%$. The maximum percentage increase in abrasion values was seen with SF0.7\%+PPF0.3\%.

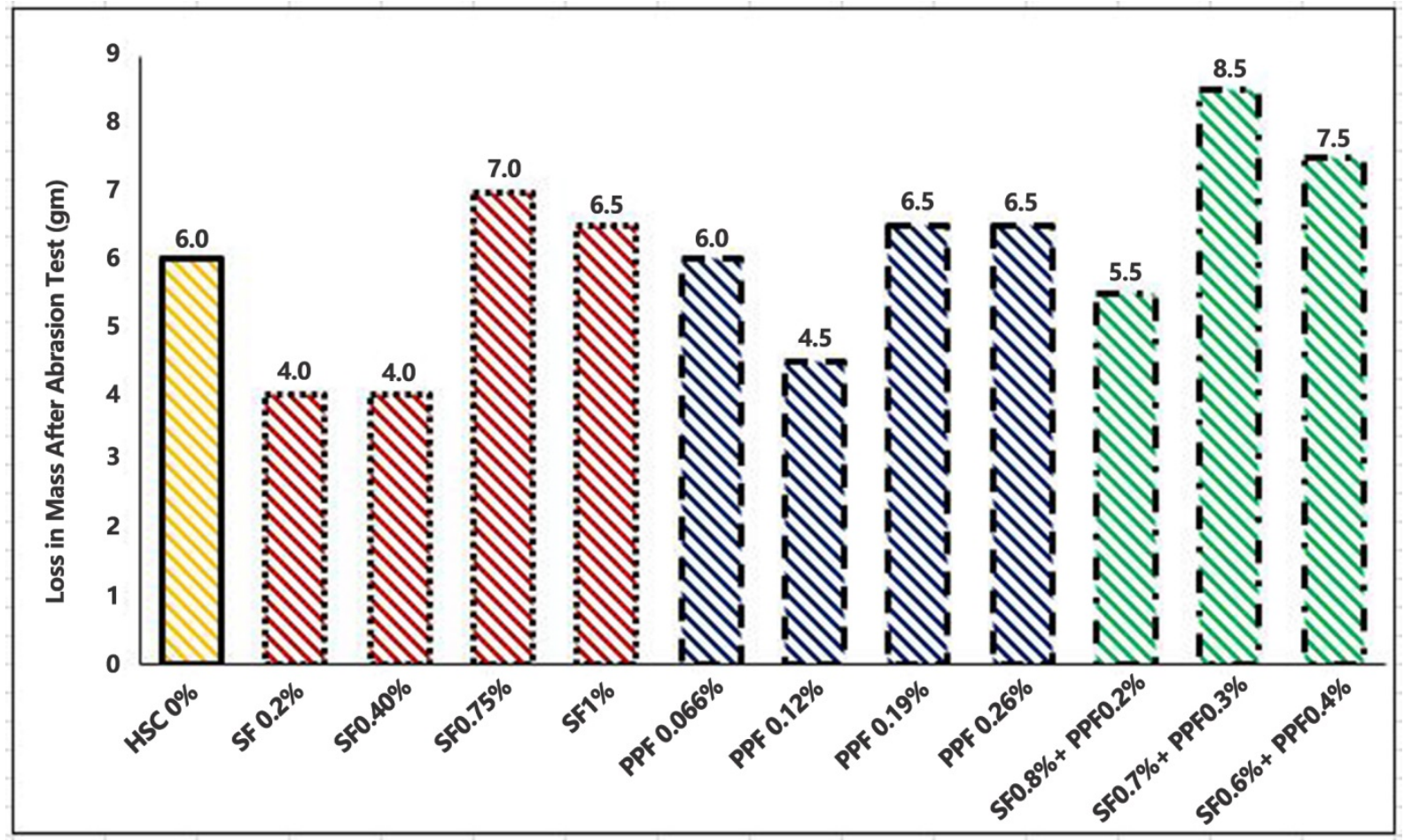

Figure 13. The Effect of Different Volume Fraction of Single Fibers and Hybrid Fibers on the Abrasion test of High Strength Concrete After 28 Days 


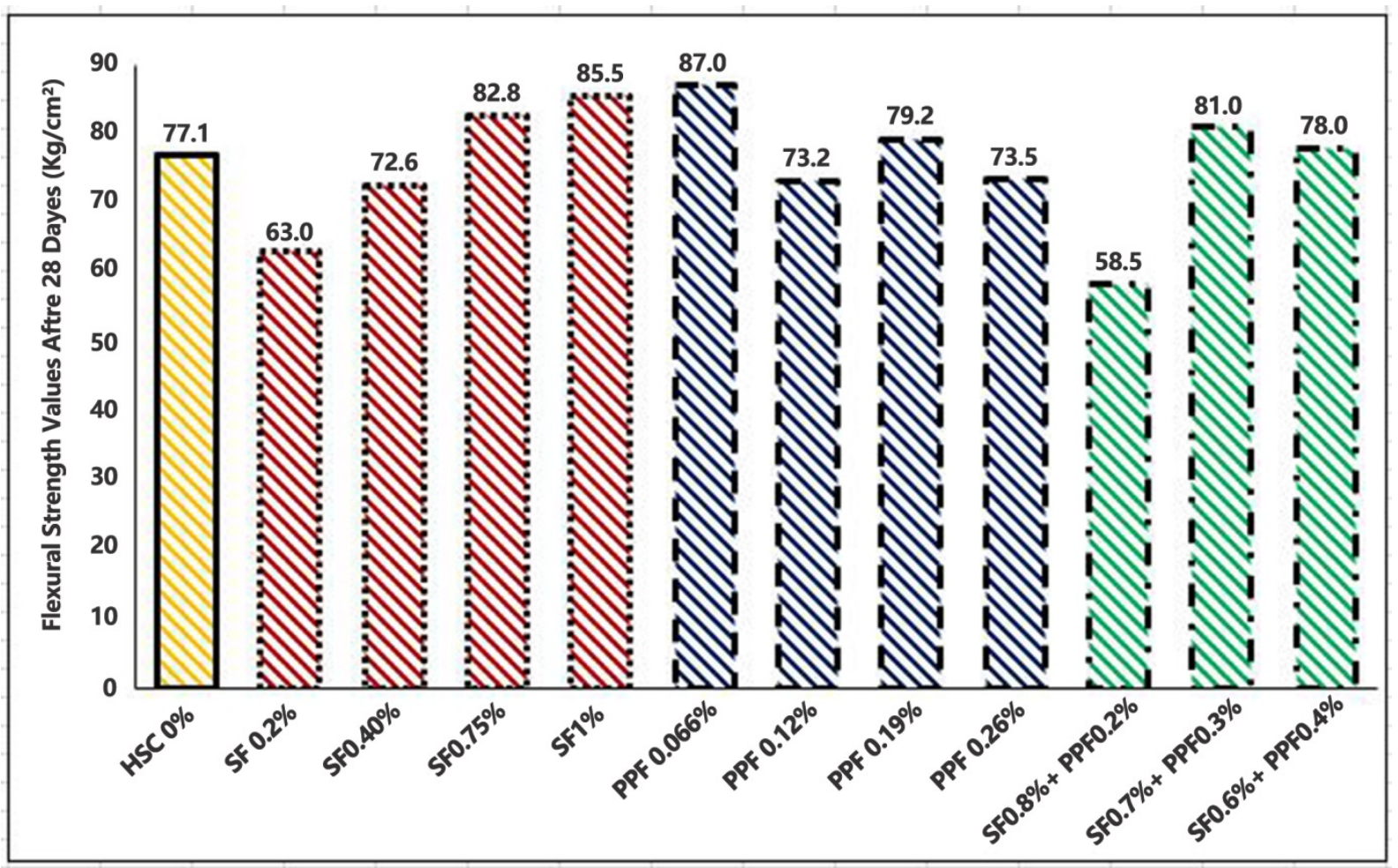

Figure 14. The Effect of Different Volume Fraction of Single Fibers and Hybrid Fibers on the Flexural Strength of High Strength Concrete After 28 Days

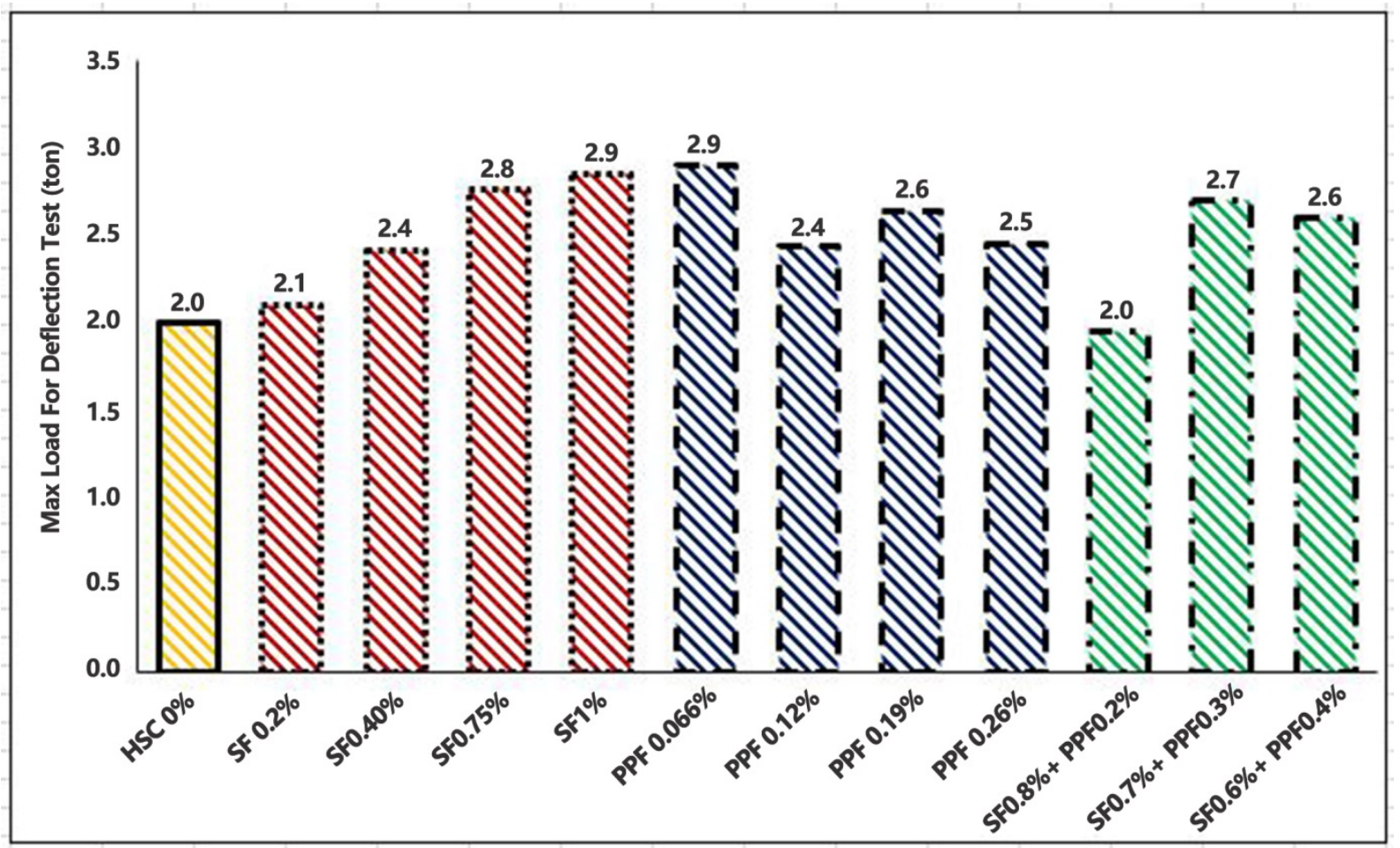

Figure 15. The Effect of Different Volume Fraction of Single Fibers and Hybrid Fibers on the Max Load Of Deflection of High Strength Concrete After 28 Days

\subsection{Flexural Test}

[23] defined flexural strength as the ability of a material to resist deformation under a load; this provides two useful parameters. The first parameter is the first crack strength that the material can withstand, and the second parameter is the ultimate flexural strength or modulus of 
rupture, which is determined by the maximum load that can be supported.

Table 4, as well as Figures 14 and15, shows the flexural strength and maximum load for deflection (ton) for all concrete mixes. Figure 16, 17, 18 and 19 shows the bending test and shape of crack for HSC, steel fibers, polypropylene fibers and hybrid fibers respectively after loading.

The results from the concrete mix containing up to $0.2 \%$ of steel fiber show a decrease in the flexural strength by $18.29 \%$ than the control mix. This could be due to the physical difficulties in fiber orientation to provide a homogenous distribution of fibers within the concrete. It can also be observed that the use of more than $0.75 \%$ steel fibers would increase the flexural strength by $10.89 \%$ than the control mix. This could be due to an improvement in the toughness matrix.

The use of PPF in concrete by $0.066 \%$ volume of concrete increases flexural strength by $12.84 \%$ compared to the control mix. The results using hybrid fibers indicate that the concrete mix SF0.7\%+PPF $0.3 \%$ has the highest increment (up to 5.06\%) compared to the control mix.

The lower density of polypropylene fiber increased fiber availability in the hybrid fiber systems, in addition to the ability of polypropylene fibers to bridge the smaller micro and macro cracks, the increase in fiber availability in the hybrid fiber systems could explain the enhancement in flexural properties.

Finally, fibers produce high-bonding with the concrete mix. Fibers are effective in controlling the micro-cracking mechanism, which results in improved behavior in terms of smaller crack openings at peak resistance. On the other hand, the high modulus of steel fiber is effective in controlling macro-cracks over a wide range and at high-stress levels.

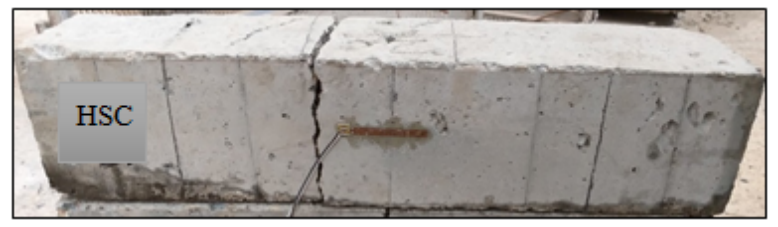

Figure 16. Crack patterns of prism for control specimen after loading

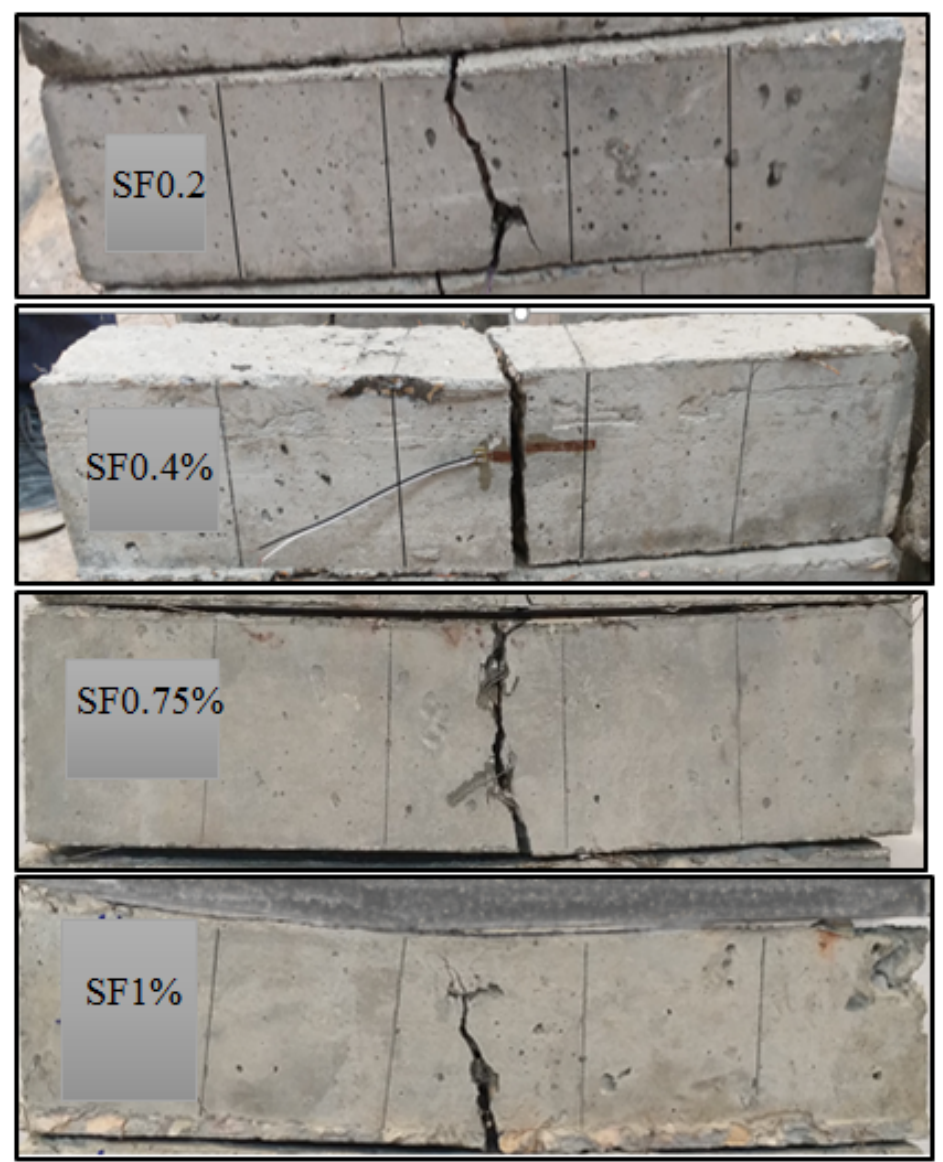

Figure 17. Crack patterns of prism with SF after loading 

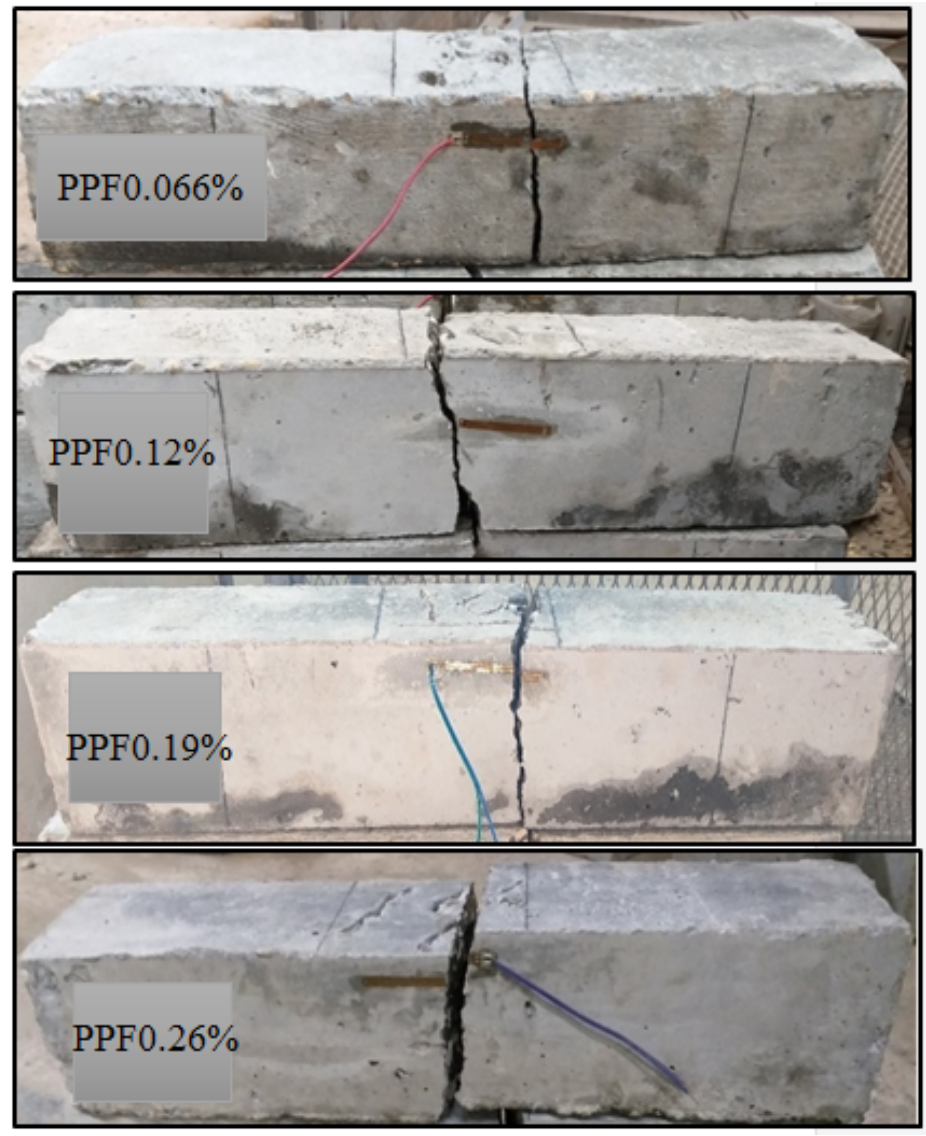

Figure 18. Crack patterns of prism with PPF after loading
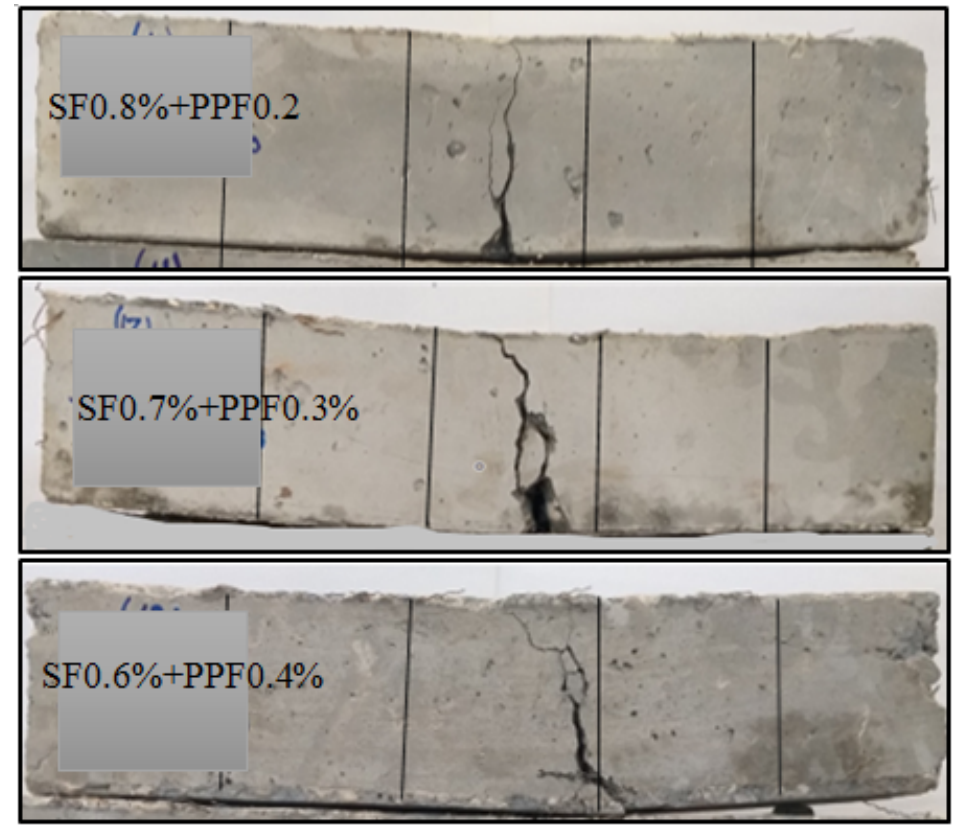

Figure 19. Crack patterns of prism with SF+PPF in hybrid after loading 


\subsection{Analyzing the Fibers after Failure}

One of the most functions of fibers inside the concrete is that it affects the mechanical properties of concrete after any collapse is a failure to the concrete sample, such as direct tension, bending, stress, shear, and fatigue. The fiber mechanism strengthening in the concrete is apparent through the strength of cohesion and interlocking between the fibers and the concrete. When loading, the stress is transmitted to the fibers and the concrete together. A crack occurs, the load is transferred to fibers only. Figure (20) showed the cracks or of the concrete sample reinforced with SF and PPF, and hybrid after the collapse. This shows that the fibers resist the formation of cracks after the failure of the concrete specimens. Figure (20a) showed the specimen of SF after failure. As it is clear that the sample after its collapse, the SF connects two parts of the concrete specimen at the place of the crack until SF reaches its maximum load, it was is cut off. As shown in figure (20 b), two parts of the specimen were separated by the failure of the PPF directly. After cracking occurs in the sample, the crack width in the SF sample increased slowly compared to the specimen reinforced with PPF. The crack behavior in the specimen reinforced with hybrid fiber is better than SF, PPF as shown in figure (20 c).

\subsection{Analytical Equations for Mechanical Parameters of All Concrete Mixtures}

The effect of changing the fiber type as well as the proportions of the mixture inside concrete on its mechanical properties has been studied, namely, the effect of using HRC and mixing ratios of both types of fiber on the mechanical properties of concrete. After studying all these variables, linear equations were reached that facilitate the knowledge of the behavior of concrete within this range easy as shown in figure 20 .

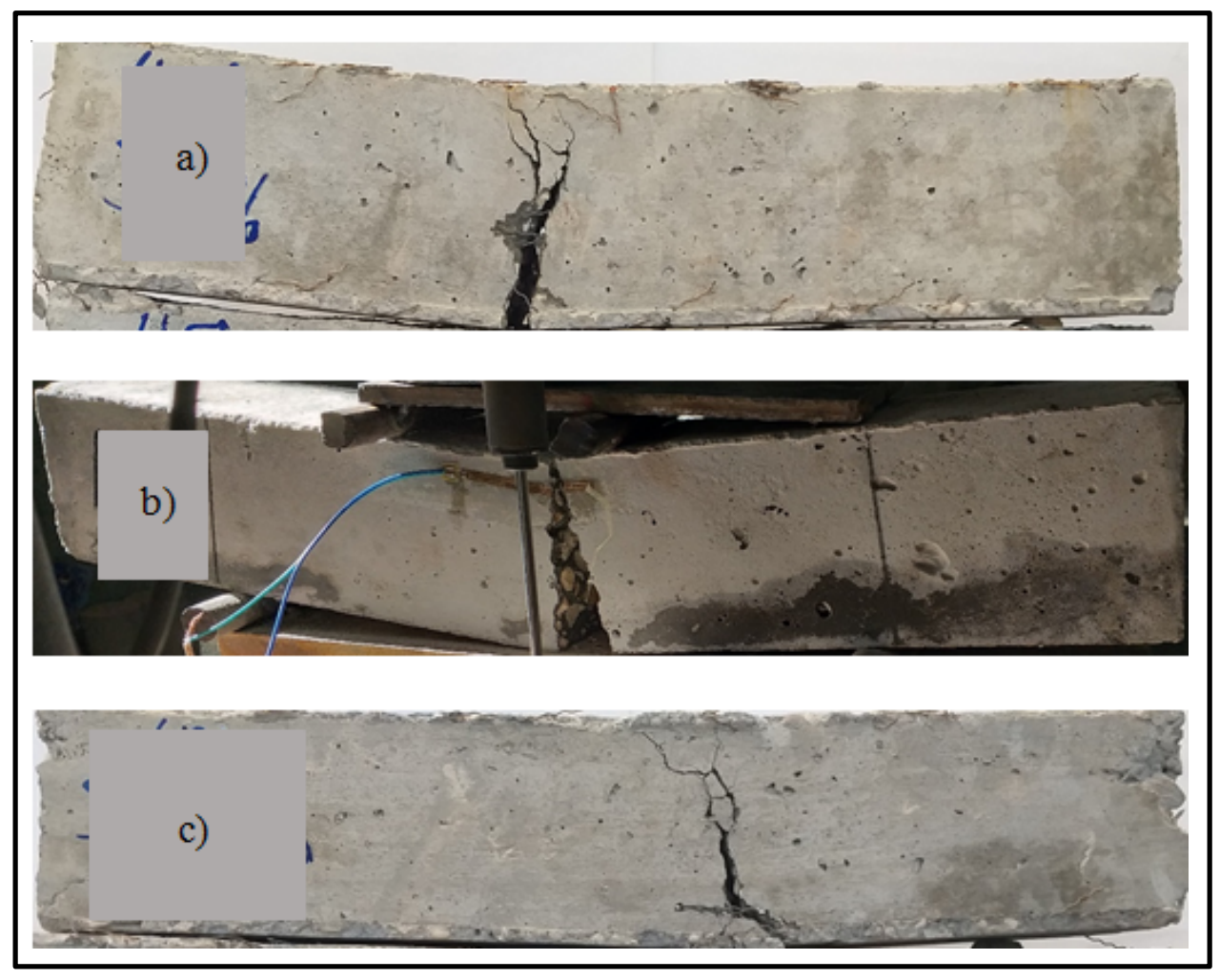

Figure 20. The behavior of the fiber and its shape after the collapse for all specimens a) SF B) PPF C) SF+PPF 

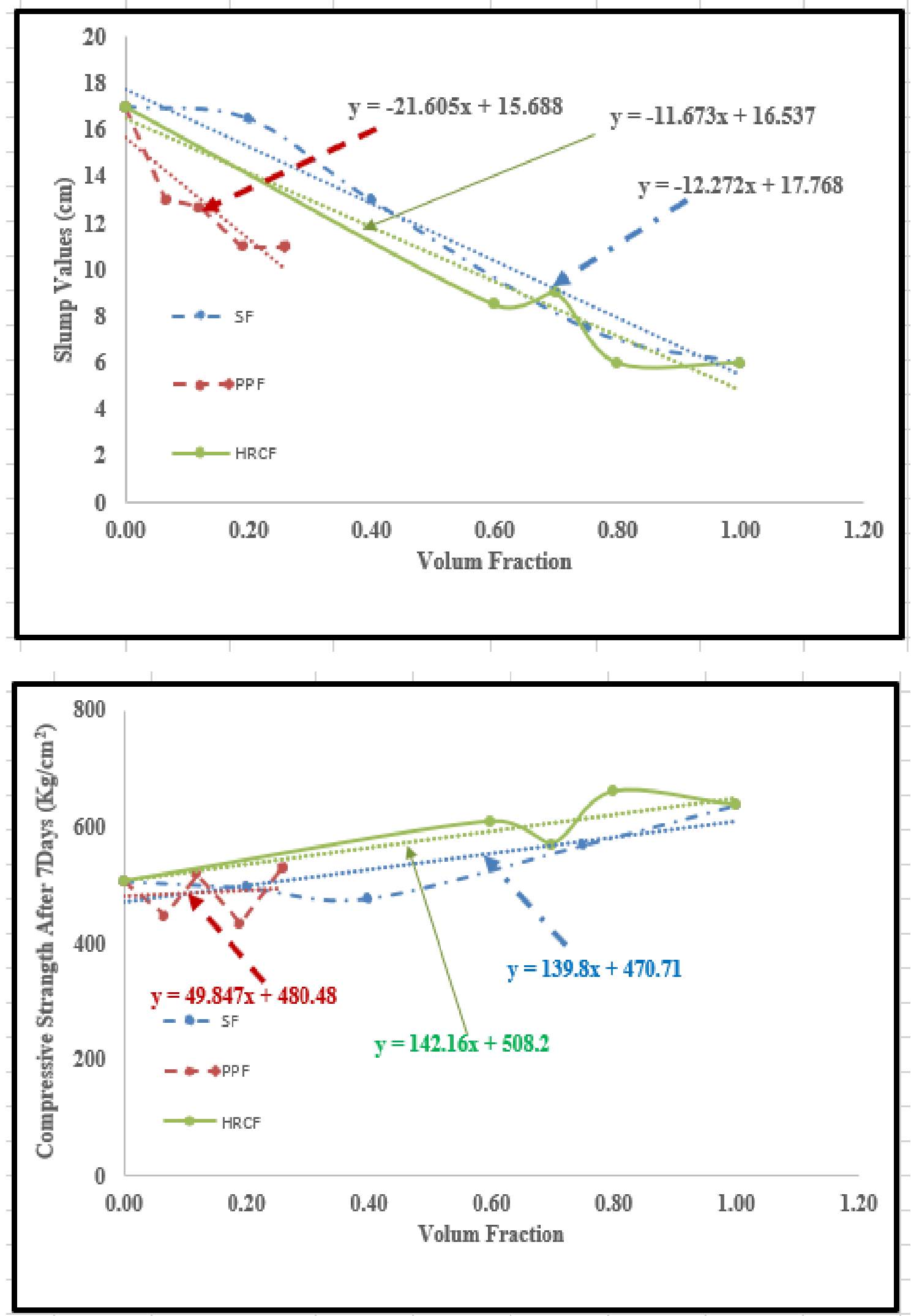

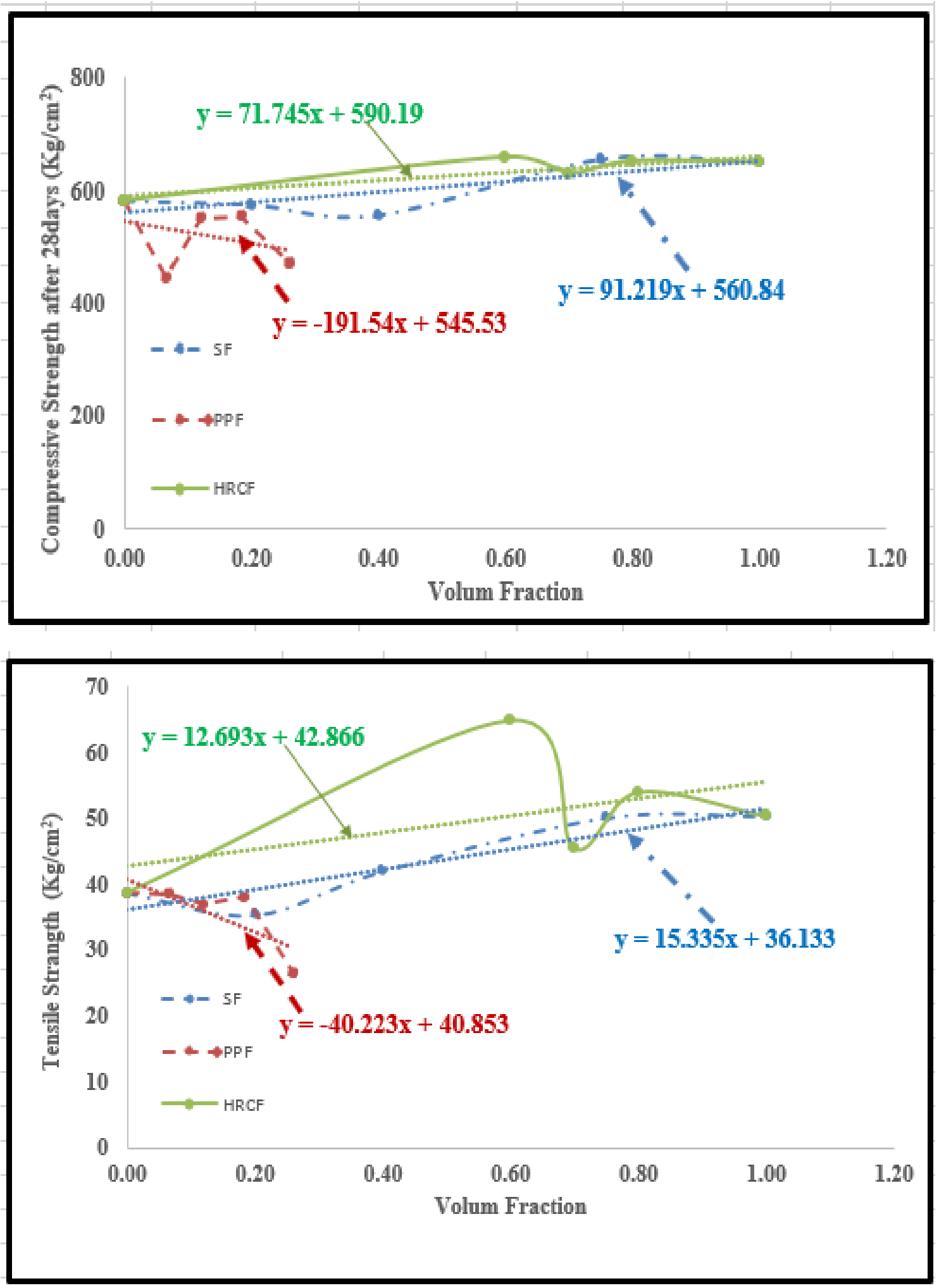

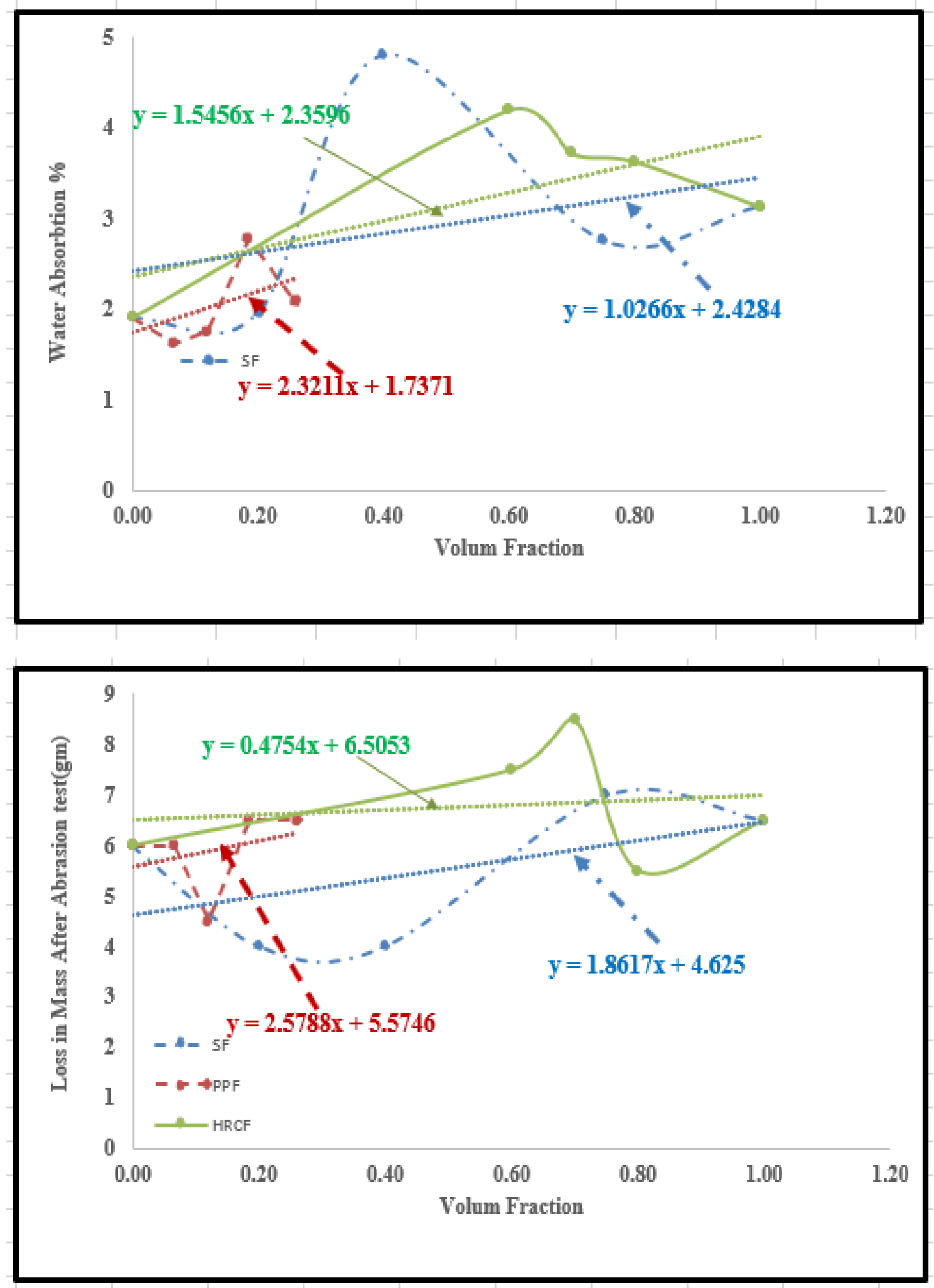

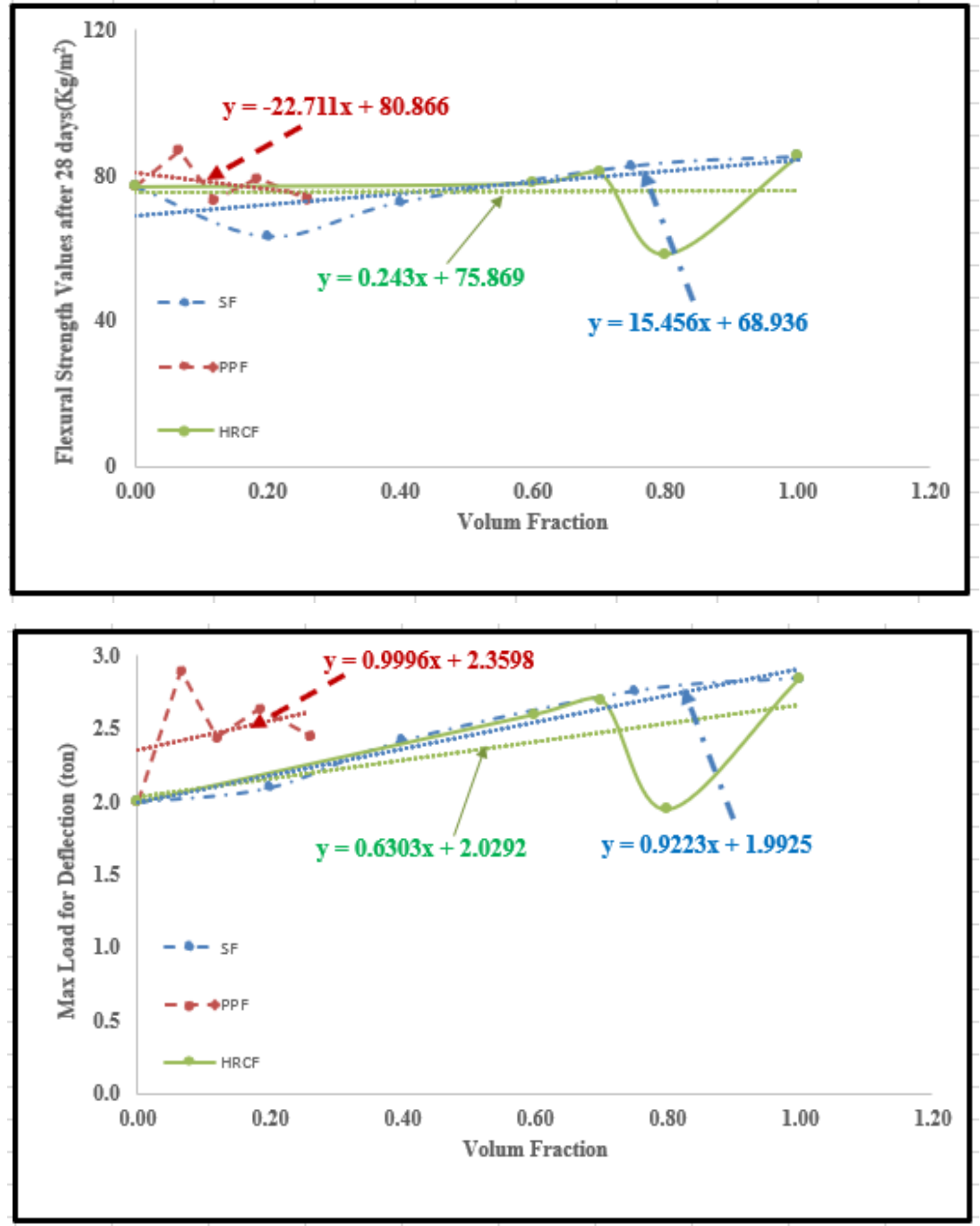

Figure 21. Equation For all mixtures a) Slump values, b) Compressive Strength after 7days, c) Compressive Strength after 28days, d) Tensile Strength, e) Water Absorption, f) Loss in Mass after Abrasion, g) Flexural Strength and h) Max Load for Deflection 
Table 5. Comparison of the results of this research with other researchers

\begin{tabular}{|c|c|c|c|c|c|c|c|c|c|c|c|}
\hline \multirow[t]{2}{*}{ Author } & \multirow{2}{*}{$\begin{array}{l}\text { Type/name } \\
\text { /Mix design }\end{array}$} & \multicolumn{2}{|c|}{ Slump $(\mathrm{cm})$} & \multicolumn{2}{|c|}{$\begin{array}{l}\text { Compressive Strength after 7days } \\
\mathrm{Kg} / \mathrm{cm}^{2}\end{array}$} & \multicolumn{2}{|c|}{$\begin{array}{c}\text { Compressive Strength after } \\
\text { 28days } \mathrm{Kg} / \mathrm{cm}^{2}\end{array}$} & \multicolumn{2}{|c|}{$\begin{array}{c}\text { Flexural Strength } \\
\mathrm{Kg} / \mathrm{cm}^{2}\end{array}$} & \multicolumn{2}{|c|}{$\begin{array}{c}\text { Split Tensile Strength } \\
\mathrm{kg} / \mathrm{cm}^{2}\end{array}$} \\
\hline & & Obtained & \%ch pc & Obtained & \%ch pc & Obtained & $\% \mathrm{ch} \mathrm{pc}$ & Obtained & $\% \mathrm{ch} \mathrm{pc}$ & Obtained & \%ch pc \\
\hline \multirow{5}{*}{ [24] } & $\mathrm{PC}$ & - & - & 335 & 0 & 620 & 0 & 95.3 & 0 & - & - \\
\hline & SF0.5\% & - & - & 325 & -2.98 & 605 & -2.42 & 93.8 & -1.57 & - & - \\
\hline & SF1\% & - & - & 335 & 0 & 645 & 4.03 & 103.5 & 8.6 & - & - \\
\hline & PPF0.025\% & - & - & 318 & -5.07 & 575 & -7.26 & 95.8 & 0.52 & - & - \\
\hline & PPF $0.05 \%$ & - & - & 315 & -5.97 & 545 & -12.1 & 97.4 & 2.2 & - & - \\
\hline \multirow{12}{*}{ 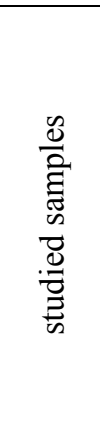 } & HSC $0 \%$ & 17 & 0 & 505.7 & 0 & 582.0 & 0 & 77.1 & 0 & 38.74 & 0 \\
\hline & SF $0.2 \%$ & 17 & 0 & 494.9 & -2.13 & 575.2 & -1.17 & 57 & -26.07 & 35.34 & 35.34 \\
\hline & SF $0.40 \%$ & 13 & -23.5 & 476.5 & -5.77 & 556.6 & -4.37 & 78.6 & 1.95 & -8.77 & -8.77 \\
\hline & SF $0.75 \%$ & 7.5 & -55.9 & 568.0 & 12.32 & 654.8 & 12.5 & 51 & -33.85 & 42.01 & 42.01 \\
\hline & SF $1 \%$ & 6 & -64.7 & 637.0 & 25.96 & 650.0 & 11.68 & 55.5 & -28.02 & 8.44 & 8.44 \\
\hline & PPF $0.066 \%$ & 13 & -23.5 & 447.0 & -11.61 & 446.2 & -23.33 & 87 & 12.84 & 38.53 & -0.54 \\
\hline & PPF $0.12 \%$ & 12.7 & -25.9 & 518.7 & 2.57 & 551.0 & -5.33 & 73.2 & -5.06 & 36.94 & -4.65 \\
\hline & PPF $0.19 \%$ & 11 & -35.3 & 433.7 & -14.24 & 554.8 & -4.67 & 79.2 & 2.72 & 38.18 & -1.44 \\
\hline & PPF $0.26 \%$ & 11 & -35.3 & 529.0 & 4.61 & 472.8 & -18.77 & 67.5 & -12.45 & 26.50 & -31.60 \\
\hline & SF0.8\%+PPF $0.2 \%$ & 6 & -64.7 & 620.0 & 30.51 & 651.8 & 12 & 58.5 & -24.12 & 54.00 & 39.39 \\
\hline & SF0.7\%+PPF $0.3 \%$ & 9 & -47.0 & 570.0 & 12.72 & 630.5 & 8.33 & 81 & 5.06 & 45.50 & 17.45 \\
\hline & SF $0.6 \%+P P F 0.4 \%$ & 8.5 & -50 & 609.0 & 20.43 & 659.0 & 12.23 & 78 & 1.17 & 65.00 & 67.79 \\
\hline & & & & \multicolumn{2}{|c|}{$\begin{array}{l}\text { Compressive Strength after } 14 \text { days } \\
\qquad \mathrm{Kg} / \mathrm{cm}^{2}\end{array}$} & & & & & & \\
\hline \multirow{4}{*}[25]{} & PC & - & - & 400.8 & 0 & 436 & 0 & 43.5 & 0 & 34.8 & 0 \\
\hline & PPF $0.036 \%$ & - & - & 430 & 7.29 & 483.3 & 10.85 & 47.6 & 9.43 & 38.2 & 9.77 \\
\hline & SF1\% & - & - & 447.9 & 10.85 & 495.2 & 13.58 & 51.3 & 17.93 & 51.1 & 46.84 \\
\hline & SF $1 \%+P P F 0.036 \%$ & - & - & 458.1 & 14.30 & 510.6 & 17.11 & 58.4 & 34.25 & 53.2 & 52.87 \\
\hline \multirow{2}{*}{ [26] } & $\mathrm{pc}$ & - & - & - & - & 286 & 0 & 36 & 0 & 31.2 & 0 \\
\hline & SF1\%+PPF0.035\% & - & - & - & - & 332.4 & 16.22 & 47.5 & 31.94 & 47.1 & 50.96 \\
\hline \multirow{4}{*}[27]{} & $\mathrm{PC}$ & 6.5 & 0 & - & - & 475.3 & 0 & - & - & 27.5 & 0 \\
\hline & PPF0.15\% & 6.2 & -4.6 & - & - & 488 & 2.67 & - & - & 34.7 & 26.18 \\
\hline & SF $1.5 \%$ & 5.1 & -21.5 & - & - & 532.4 & 11.93 & - & - & 41.7 & 51.63 \\
\hline & SF $1.5 \%+$ PPF $0.15 \%$ & 4.4 & -32.3 & - & - & 537 & 12.98 & - & - & 47.6 & 73.1 \\
\hline \multirow{5}{*}[28]{} & PC & 6.6 & 0 & - & - & 636 & 0 & 76.5 & 0 & - & - \\
\hline & SF1\% & 5.9 & -10.6 & - & - & 718 & 12.9 & 93.5 & 22.2 & - & - \\
\hline & SF $1.5 \%$ & 5.8 & -12.1 & - & - & 703 & 10.5 & 99.5 & 30.06 & - & - \\
\hline & SF $1.75 \%$ & 5.7 & -13.6 & - & - & 693 & 8.96 & 108.5 & 41.8 & - & - \\
\hline & SF2.0\% & 5.6 & -15.1 & - & - & 672 & 5.7 & 104.5 & 36.6 & - & - \\
\hline
\end{tabular}


Finally, fibers have been used in recent years to increase the cracking and tensile strength of concrete. Some researchers studied the mechanical properties of RC reinforced with SF, PPF, and Hybrid fibers. Table 4 showed the comparison between the mechanical properties of RC reinforced with fibers. Table4 displayed the best percentages of SF ranged from (0.2 to $1 \%)$. Most researchers proved that the results for the mechanical properties of concrete decrease when the volume fraction of SF increases from $1 \%$. As is the case in PPF, the volume fraction of PPF rang from $(0.06 \%$ to $0.3 \%)$, which is the content is the best results for concrete. This study confirmed the importance of adding hybrid fibers to concrete because it gives better results in the mechanical properties of the concrete as shown in table 5 .

\section{Conclusions}

Experiments are carried out on fiber-reinforced concrete, and the samples were in the form of a cube, cylinder, and prism. The compressive strength, abrasion resistance, water absorption, split tensile strength, and flexural strength of the elements are compared with the hybrid fiber reinforced concrete. The following conclusions may be drawn.

1. The addition of fibers at concrete mixture decreases the value of slump of concrete. The Reduction of slump increased by the increase of the fiber content, especially illustrated in $1.0 \%$ dosage of steel fiber and (SF0.8\%+PPF $0.2 \%)$ decreased by $64.71 \%$ compared with the control mix (HSC) because of friction between fibers and aggregates which reduce the workability.

2. Superplasticizers in concrete mixtures can be used to overcome the reduction happened in workability.

3. By increasing the volume ratios of single $\mathrm{SF}$ in the concrete mix, the compressive strength and tensile strength increased by $12.5 \%, 30.20 \%$, respectively; but their values increased slightly with the increase in volume ratios of PPF compared with the control $\operatorname{mix}$ (HSC).

4. For this reason, using the hybrid fiber achieve an increase by $20.4 \%$ at an early age ( 7 days) and $13.23 \%$ at 28 days in the compressive strength, increase by $67.79 \%$ at tensile strength compared with the control mix (HSC).

5. Permeability of concrete increased by adding fiber. The maximum percentage increase in water absorption values with SF0.4\% was $151.89 \%$, with PPF0.02\% was $45.64 \%$ and with SF0.6\%+PPF0.4\% were $325.54 \%$ compared with the control mix.

6. Adding fibers in concrete mixes are more effective in the abrasion behavior of HSC. The maximum percentage increases in abrasion test values compared with the control mix with SF0.75\% was
$16.67 \%$, with PPF $0.75 \%$ was $8.33 \%$ and with SF $0.7 \%+$ PPF $0.3 \%$ was $41.67 \%$.

7. The flexural strength of concrete is tested by beams after 28 days for concrete with SF, PPF and hybrid fibers increased by $10.89 \%, 12.84 \%$ and $5.06 \%$, respectively compared with the control mix.

\section{REFERENCES}

[1] H. Li, M.-h. Zhang, and J.-p. Ou, "Abrasion resistance of concrete containing nano-particles for pavement," Wear, vol. 260, pp. 1262-1266, 2006.

[2] R. Nilforoush, M. Nilsson, and L. Elfgren, "Experimental evaluation of tensile behaviour of single cast-in-place anchor bolts in plain and steel fibre-reinforced normal-and high-strength concrete," Engineering Structures, vol. 147, pp. 195-206, 2017.

[3] S. Chikhalikar and S. Tande, "An experimental investigation on characteristics properties of fibre reinforced concrete containing waste glass powder as pozzolona," in 37th Conference on Our World in Concrete and Structures, Singapore, August, 2012.

[4] L. Prudencio, S. Austin, P. Jones, H. Armelin, and P. Robins, "Prediction of steel fibre reinforced concrete under flexure from an inferred fibre pull-out response," Materials and Structures, vol. 39, pp. 601-610, 2006.

[5] A. M. Brandt, "Fibre reinforced cement-based (FRC) composites after over 40 years of development in building and civil engineering," Composite Structures, vol. 86, pp. 3-9, 2008.

[6] S. Ivorra, P. Garcés, G. Catalá, L. G. Andión, and E. Zornoza, "Effect of silica fume particle size on mechanical properties of short carbon fiber reinforced concrete," Materials \& Design, vol. 31, pp. 1553-1558, 2010.

[7] S. Elshafie and G. Whittleston, "A review of the effect of basalt fibre lengths and proportions on the mechanical properties of concrete," International Journal of Research in Engineering and Technology, vol. 4, pp. 458-465, 2015.

[8] M. Alberti, A. Enfedaque, J. Gálvez, M. Cánovas, and I. Osorio, "Polyolefin fiber-reinforced concrete enhanced with steel-hooked fibers in low proportions," Materials \& Design, vol. 60, pp. 57-65, 2014.

[9] R. Singaravadivelan, N. Sakthieswaren, and K. Muthuramu, "Experimental Investigation on the Behaviour of Flexural Strengthening of Beam Using Basalt Fiber," in International Conference on Automotive, Mechanical and Materials Engineering (ICAMME'2012) Penang (Malaysia) May, 2012, pp. 19-20.

[10] A. Caverzan, E. Cadoni, and M. Di Prisco, "Dynamic tensile behaviour of self compacting steel fibre reinforced concrete," in Applied Mechanics and Materials, 2011, pp. 220-225.

[11] T. Lok and P. Zhao, "Impact response of steel fiber-reinforced concrete using a split Hopkinson pressure bar," Journal of Materials in Civil Engineering, vol. 16, pp. 54-59, 2004. 
[12] S. Goel, S. Singh, and P. Singh, "Flexural fatigue strength and failure probability of self compacting fibre reinforced concrete beams," Engineering Structures, vol. 40, pp. 131-140, 2012.

[13] M. Tumadhir, "Thermal and mechanical properties of basalt fibre reinforced concrete," International Journal of Civil and Environmental Engineering, vol. 7, pp. 334-337, 2013.

[14] M. Alberti, A. Enfedaque, and J. Gálvez, "Comparison between polyolefin fibre reinforced vibrated conventional concrete and self-compacting concrete," Construction and Building Materials, vol. 85, pp. 182-194, 2015.

[15] M. Alberti, A. Enfedaque, and J. Gálvez, "On the mechanical properties and fracture behavior of polyolefin fiber-reinforced self-compacting concrete," Construction and Building Materials, vol. 55, pp. 274-288, 2014.

[16] K. Behfarnia and A. Behravan, "Application of high performance polypropylene fibers in concrete lining of water tunnels," Materials \& Design, vol. 55, pp. 274-279, 2014.

[17] K. Kawashima, R. Zafra, T. Sasaki, K. Kajiwara, and M. Nakayama, "Effect of polypropylene fiber reinforced cement composite and steel fiber reinforced concrete for enhancing the seismic performance of bridge columns," Journal of Earthquake Engineering, vol. 15, pp. 1194-1211, 2011.

[18] D.-Y. Yoo, S.-W. Kim, and J.-J. Park, "Comparative flexural behavior of ultra-high-performance concrete reinforced with hybrid straight steel fibers," Construction and Building Materials, vol. 132, pp. 219-229, 2017.

[19] Y. Chi, M. Yu, L. Huang, and L. Xu, "Finite element modeling of steel-polypropylene hybrid fiber reinforced concrete using modified concrete damaged plasticity," Engineering Structures, vol. 148, pp. 23-35, 2017.

[20] P. Song, J. Wu, S. Hwang, and B. Sheu, "Statistical analysis of impact strength and strength reliability of steelpolypropylene hybrid fiber-reinforced concrete," Construction and Building Materials, vol. 19, pp. 1-9, 2005.

[21] L. Huang, L. Xu, Y. Chi, and H. Xu, "Experimental investigation on the seismic performance of steelpolypropylene hybrid fiber reinforced concrete columns," Construction and Building Materials, vol. 87, pp. 16-27, 2015.

[22] E. Code, "Egyptian Code of Practice for Concrete Structures, HBRC," Arabic, Cairo, Egypt, 2007.

[23] S. M. Elayesh, "Performance of laterite aggregate concrete," Universiti Teknologi Malaysia, 2009.

[24] N. Kabashi, K. Cenë, R. Hadri, and A. Sadikaj, "Effect of Fibre Reinforced Concrete and Behaviour in Rigid Pavement," 2018.

[25] R. B. Vibhuti and N. Aravind, "Mechanical properties of hybrid fiber reinforced concrete for pavements," 2013.

[26] G. Asok and S. George, "Investigation on hybrid concrete using steel and polypropylene fiber," International Journal of New Technology and Research, vol. 2, 2016.

[27] B. Li, Y. Chi, L. Xu, Y. Shi, and C. Li, "Experimental investigation on the flexural behavior of steel-polypropylene hybrid fiber reinforced concrete," Construction and Building Materials, vol. 191, pp. 80-94, 2018.

[28] E. T. Dawood and M. Ramli, "Contribution of hybrid fibers on the properties of high strength concrete having high workability," Procedia Engineering, vol. 14, pp. 814-820, 2011.

[29] Quoc Gia Hoang, Quoc Vuong Vu , "Estimation the Initial Cement Dosage of Concrete from Mechanical Behavior and Chemical Analysis," Civil Engineering and Architecture, Vol. 8, No. 4, pp. 580 - 585, 2020. DOI: $10.13189 /$ cea.2020.080422. 